\title{
Desmídias perifíticas de cinco lagoas do Distrito Federal, Brasil: I - Gênero Cosmarium Corda ex Ralfs
}

\author{
Lillian Mércia Benevenuto Estrela ${ }^{1}$, Bárbara Medeiros Fonseca ${ }^{1,3}$ e \\ Carlos Eduardo de Mattos Bicudo²
}

Recebido: 8.02.2011; aceito: 10.11.2011

\begin{abstract}
Periphytic desmids from five lagoons of the Federal District, Brazil: I - Genus Cosmarium Corda ex Ralfs). This study aimed a taxonomic survey on genus Cosmarium in five oligotrophic lagoons in the Federal District, Brazil: Lagoa Bonita, Lagoa Joaquim Medeiros, Lagoa do Cedro, Lagoa Taquara and Lagoa dos Gansos. Samples were realized between 2006 and 2009, by macrophytes squeezing and/or submerged substrates scraping; 18 samples were analyzed and deposited at the Herbarium of the University of Brasília. They were fixed in formalin solution (4\%) and analized under 400× and $1000 \times$ magnification. Altogether 42 taxons were found. Among them, 30 are cited for the first time in the Federal District and probably eight for Brazil. Lagoa Bonita had the higher number of taxa (32), followed by Lagoa Joaquim Medeiros (19), Lagoa do Cedro (16), Lagoa dos Gansos (15) e Lagoa Taquara (9). Cosmarium pseudopyramidatum var. pseudopyramidatum Lundell was the most common taxon, present in $100 \%$ of the samples.
\end{abstract}

Key words: algae, Brasília, Cerrado, periphyton, Zygnemaphyceae

RESUMO - (Desmídias perifíticas de cinco lagoas do Distrito Federal, Brasil: I - Gênero Cosmarium Corda ex Ralfs). Teve-se como objetivo realizar o levantamento taxonômico do gênero Cosmarium de cinco lagoas oligotróficas do Distrito Federal: Lagoa Bonita, Lagoa Joaquim Medeiros, Lagoa do Cedro, Lagoa Taquara e Lagoa dos Gansos. As coletas foram realizadas entre 2006 e 2009, por meio do espremido de macrófitas e/ou raspagem de substratos submersos, num total de 18 amostras depositadas no Herbário da Universidade de Brasília. O material coletado foi fixado em formalina a 4\% e analisado sob aumentos de 400× e 1000×. Foram registrados 42 táxons. Desses, 30 são citações pioneiras para o DF e oito provavelmente para o Brasil. A Lagoa Bonita apresentou o maior número de táxons (32), seguida pela Lagoa Joaquim Medeiros (19), Lagoa do Cedro (16), Lagoa dos Gansos (15) e Lagoa Taquara (9). Cosmarium pseudopyramidatum var. pseudopyramidatum Lundell foi o táxon mais comum, presente em 100\% das amostras.

Palavras-chave: algas, Brasília, Cerrado, perifíton, Zygnemaphyceae

\section{Introdução}

O gênero Cosmarium é constituído por células solitárias, de vida livre, desde muito pouco até profundamente constritas na parte média e seção transversal da célula elíptica, oblonga ou reniforme, raramente circular (Bicudo \& Menezes 2006). Dentre as publicações mais completas sobre Cosmarium destaca-se a de Prescott et al. (1981), sobre as espécies da América do Norte. No Brasil, há vários trabalhos taxonômicos sobre desmídias em geral, incluindo o gênero abordado no presente estudo (e.g., Bicudo 1969, Sophia \& Huszar 1996, Marinho \& Sophia 1997,
Sophia 1999, Lopes \& Bicudo 2003, Sophia et al. 2005, Felisberto \& Rodrigues 2008). Particularmente em relação a ambientes de Cerrado do Brasil central, destaca-se o levantamento florístico de Förster (1964). Entre os trabalhos que tratam exclusivamente do gênero, estão Silva \& Cecy (2004), Felisberto \& Rodrigues (2004, 2010b), Bortolini et al. (2010) e Araújo \& Bicudo (2006). Em geral, as citações aparecem esparsas em trabalhos florísticos mais amplos.

Apesar de existirem vários estudos que fazem menção às algas do gênero Cosmarium para ambientes do Distrito Federal (DF), apenas os

1. Universidade Católica de Brasília, Curso de Ciências Biológicas, Sala E-10, QS 07, Lote 01, 71966-700 Águas Claras, Taguatinga, DF, Brasil

2. Instituto de Botânica, Núcleo de Pesquisa em Ecologia, Caixa Postal 68041, 04045-972 São Paulo, SP, Brasil

3. Autor para correspondência: bm_fonseca@yahoo.com.br 
trabalhos ecológicos de Oliveira \& Krau (1970) e Giani \& Pinto Coelho (1986), realizados no Lago Paranoá, foram publicados. Os demais trabalhos são estudos sobre ecologia do fitoplâncton que abordam os representantes desses gêneros em levantamentos florísticos amplos e estão concentrados em relatórios, teses e dissertações (Cronberg 1977, Giani 1984, Leite 1990, Murakami 2000, Abreu 2001, Oliveira 2004, Mendonça-Galvão 2005, Gomes 2007, Philomeno 2007). Desses, a maioria sem fotos ou ilustrações e alguns sem identificação infra-genérica. Além disso, inexistem artigos científicos sobre as lagoas do Cedro, Taquara e dos Gansos, todas elas formadas em áreas de campo úmido, tão comuns no Cerrado brasileiro (Padovesi-Fonseca 2005). Nesse contexto, o presente trabalho teve como objetivo realizar o levantamento taxonômico das desmídias perifíticas do gênero Cosmarium de cinco lagoas do DF, trazendo uma revisão sobre esse táxon na região.

\section{Material e métodos}

Área de estudo - Os ambientes lênticos amostrados localizam-se no Distrito Federal (DF), região central do Brasil, no bioma Cerrado (figura 1). O clima da região é do tipo Aw (classificação de Köppen), ou seja, tropical chuvoso, com duas estações bem definidas: uma quente e chuvosa, de outubro a março (temperatura média do ar em torno de $29{ }^{\circ} \mathrm{C}$ ) e uma fria e seca, de abril a setembro (temperatura média do ar em torno de $18{ }^{\circ} \mathrm{C}$ ). A precipitação media anual é de aproximadamente $1.500 \mathrm{~mm}$, variando de $750 \mathrm{a}$ $2.000 \mathrm{~mm}$ (Silva et al. 2008).

As cinco lagoas estudadas foram: Lagoa Bonita, Lagoa Joaquim Medeiros, Lagoa do Cedro, Lagoa Taquara e Lagoa dos Gansos (tabela 1, figura 1). Com exceção da Lagoa do Cedro, localizada na unidade hidrográfica do rio Paranoá, as demais lagoas integram a unidade hidrográfica do rio São Bartolomeu. Todas elas, por sua vez, fazem parte da grande bacia do Paraná. A Lagoa Bonita e a Lagoa Joaquim Medeiros são as maiores, com área de 0,8 e $0,3 \mathrm{~km}^{2}$, respectivamente. As demais apresentam área superficial inferior a $0,01 \mathrm{~km}^{2}$. São ambientes rasos, com menos de $3 \mathrm{~m}$ de profundidade máxima. Todas têm características oligotróficas (dados de nutrientes ainda não publicados). A Lagoa Bonita localiza-se dentro da Estação Ecológica de Águas Emendadas. As demais, em áreas rurais ou afastadas do centro de Brasília. A Lagoa do Cedro é a que sofre maior impacto antrópico dentre as lagoas, por ser

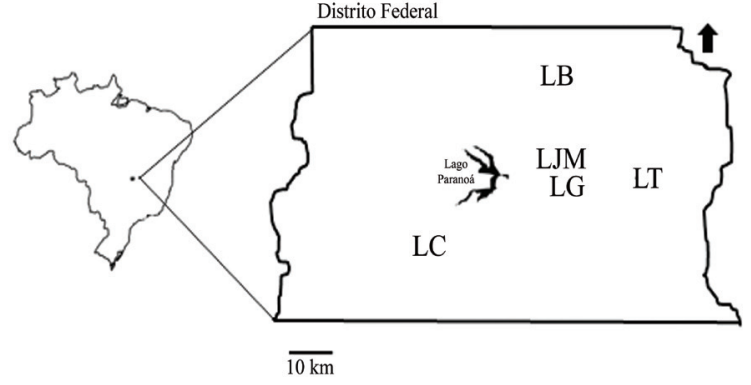

Figura 1. Mapa do Distrito Federal, Brasil, com a localização das cinco lagoas estudadas (LB: Lagoa Bonita, LJM: Lagoa Joaquim Medeiros, LG: Lagoa dos Gansos, LT: Lagoa Taquara, LC: Lagoa do Cedro).

Figure 1. Map of the Federal District, Brazil, with location of the five lagoons studied (LB: Lagoa Bonita, LJM: Lagoa Joaquim Medeiros, LG: Lagoa dos Gansos, LT: Lagoa Taquara, LC: Lagoa do Cedro).

de mais fácil acesso à população. Segundo análises feitas ainda no campo, no momento da coleta, com auxílio de sondas da marca YSI, os locais amostrados caracterizam-se por $\mathrm{pH}$ de neutro e ligeiramente ácido e baixa condutividade (em geral $<20 \mu \mathrm{S} \mathrm{cm}^{-1}$ ).

Amostragem e análise laboratorial - O levantamento taxonômico foi realizado com base na análise de 18 amostras provenientes de coletas em anos $(2006,2008,2009)$ e estações distintas (seca: agosto e setembro; chuva: março a maio). Ao todo, foram quatro amostras para as lagoas do Cedro, dos Gansos e Joaquim Medeiros, e três amostras para as lagoas Taquara e Bonita (tabela 1).

As amostragens foram todas realizadas na zona litorânea, num único ponto para cada lagoa. O material perifítico foi obtido de diferentes tipos de substratos. Pedras e folhas foram escovadas e lavadas com água destilada, enquanto macrófitas foram espremidas ou escovadas. Ainda no campo, as amostras foram preservadas em solução aquosa de formalina com concentração final entre 3 e 5\%. Para a identificação dos táxons foram registradas as medidas celulares e características morfológicas e reprodutivas, utilizando-se microscópio de marca Olympus modelo CX 31, equipado com ocular micrometrada, sob aumentos de $400 \times$ e $1000 \times$. Os indivíduos foram fotografados com máquina digital Sony Cyber-Shot, modelo DSC-W55 7.2MP. A análise do material coletado foi realizada no Laboratório de Botânica da Universidade Católica de Brasília.

O estudo taxonômico foi realizado a partir de análise populacional (cerca de 10 lâminas para cada 
Tabela 1. Lagoas do Distrito Federal amostradas neste estudo e suas respectivas coordenadas geográficas, acompanhadas de variáveis limnológicas (Temp: temperatura da água, OD: oxigênio dissolvido, Cond: condutividade elétrica).

Table 1. Lagoons from the Federal District sampled in this study and their respective geographic coordinates, with limnological variables (Temp: water temperature, OD: dissolved oxygen, Cond: electrical conductivity).

\begin{tabular}{|c|c|c|c|c|c|c|}
\hline Lagoa & Coordenadas & Data & $\begin{array}{l}\text { Temp } \\
\left({ }^{\circ} \mathrm{C}\right)\end{array}$ & $\begin{array}{c}\mathrm{OD} \\
\left(\mathrm{mg} \mathrm{L}^{-1}\right)\end{array}$ & $\mathrm{pH}$ & $\begin{array}{c}\text { Cond } \\
\left(\mu \mathrm{S} \mathrm{cm}^{-1}\right)\end{array}$ \\
\hline \multirow{3}{*}{ Lagoa Bonita } & \multirow{3}{*}{$\begin{array}{l}15^{\circ} 35^{\prime} 22,4{ }^{\prime \prime} \mathrm{S} \\
47^{\circ} 41^{\prime} 49,0 \text { ' } \mathrm{O}\end{array}$} & $25-\mathrm{VIII}-2006$ & 24,7 & 5,2 & 6,0 & 2,0 \\
\hline & & $27-V-2008$ & 26,5 & 4,3 & 6,2 & 9,6 \\
\hline & & 10-III-2009 & 27,6 & 5,4 & 6,3 & 7,0 \\
\hline \multirow{4}{*}{$\begin{array}{l}\text { Lagoa Joaquim } \\
\text { Medeiros }\end{array}$} & \multirow{4}{*}{$\begin{array}{l}15^{\circ} 38^{\prime} 15,9{ }^{\prime \prime} \mathrm{S} \\
47^{\circ} 41^{\prime} 29,5 " \mathrm{O}\end{array}$} & 08-VIII-2006 & 27,0 & 5,3 & 6,9 & 19,0 \\
\hline & & 22-VIII-2008 & 30,6 & 4,2 & 6,3 & 3,5 \\
\hline & & 25-IV-2008 & 29,2 & 4,7 & 7,9 & - \\
\hline & & 10-III-2009 & 28,6 & 4,0 & 7,3 & 4,5 \\
\hline \multirow{4}{*}{ Lagoa do Cedro } & \multirow{4}{*}{$\begin{array}{l}15^{\circ} 53^{\prime} 49,7^{\prime \prime} \mathrm{S} \\
47^{\circ} 56^{\prime} 36,6 ” \mathrm{O}\end{array}$} & 19-IX-2006 & 24,0 & 4,3 & 6,1 & 18,0 \\
\hline & & 22-IV-2008 & 27,3 & 5,1 & 7,3 & 25,4 \\
\hline & & 19-IX-2008 & 27,0 & 5,0 & 6,3 & 15,7 \\
\hline & & 03-III-2009 & 29,5 & 5,5 & 7,3 & 33,2 \\
\hline \multirow{3}{*}{ Lagoa Taquara } & \multirow{3}{*}{$\begin{array}{l}15^{\circ} 38^{\prime} 12,4{ }^{\prime \prime} \mathrm{S} \\
47^{\circ} 31^{\prime} 22,0 " \mathrm{O}\end{array}$} & 15-VIII-2006 & 23,8 & 4,9 & 6,4 & 13,0 \\
\hline & & $06-V-2008$ & 24,9 & 4,8 & 6,7 & 13,7 \\
\hline & & 29-VIII-2008 & 21,8 & 5,5 & 7,7 & 29,2 \\
\hline \multirow{4}{*}{ Lagoa dos Gansos } & \multirow{4}{*}{$\begin{array}{l}15^{\circ} 40^{\prime} 33,1^{\prime \prime} \mathrm{S} \\
47^{\circ} 41^{\prime} 37,4{ }^{\prime \prime} \mathrm{O}\end{array}$} & 08-VIII-2006 & 24,8 & 5,0 & 5,9 & 16,0 \\
\hline & & $02-V-2008$ & 22,0 & 4,5 & 5,2 & 13,8 \\
\hline & & 05-IX-2008 & 28,1 & - & 6,2 & 7,5 \\
\hline & & 20-III-2009 & 30,7 & 4,0 & 7,2 & 8,7 \\
\hline
\end{tabular}

amostra) na qual se observaram variações morfológicas com base em referências clássicas e recentes, tais como: Förster (1964, 1969, 1974), Borge (1899, 1903, 1918, 1924), Prescott et al. (1981), Silva \& Cecy (2004), Felisberto \& Rodrigues (2004, 2008, 2010b), Araújo (2006), Araújo \& Bicudo (2006). Para cada indivíduo encontrado foram registradas medidas de comprimento (compr.), largura total (larg.) e largura do istmo. As amostras foram depositadas no Herbário da Universidade de Brasília (UB). Os táxons foram classificados em pequenos (compr. 6-20 $\mu \mathrm{m}$ ), médios (compr. 21-35 $\mu \mathrm{m}$ ) e grandes (compr. $>35 \mu \mathrm{m})$, de acordo com Araújo \& Bicudo (2006).

\section{Resultados e Discussão}

Foram registrados 42 táxons, com 30 citações pioneiras para o DF e oito provavelmente para o Brasil. Os mesmos estão marcados com um (pioneira para o DF) ou dois asteriscos (pioneira para o Brasil) na descrição das espécies. Considerando todo o período de estudo, a Lagoa Bonita apresentou o maior número de táxons (32), seguida pela Lagoa Joaquim Medeiros (19), Lagoa do Cedro (16), Lagoa dos Gansos (15) e Lagoa Taquara (9). A relação dos táxons presentes em cada amostra encontra-se na tabela 2. O táxon mais comum foi Cosmarium pseudopyramidatum var. pseudopyramidatum Lundell, presente em 100\% das amostras analisadas.

A Lagoa Bonita foi a que apresentou maior número de táxons exclusivos (7): $C$. denticulatum Borge var. ovale Grönblad, C. denticulatum Borge var. triangulare Grönblad, C. exiguum Archer var. exiguum f. exiguum, $C$. laeve Rabenhorst var. acervatum Förster, C. ocellatum Eichler \& Gutwinski var. brasiliense Förster, C. ordinatum (Börgesen) West \& West var. ordinatum f. ordinatum e C. vitiosum Scott \& Gröenblad. A Lagoa Joaquim Medeiros apresentou dois táxons exclusivos (C. sublobatum (Brébisson) Archer 
var. brasiliense Borge e C. subspeciosum Nordstedt var. subspeciosum), assim como a Lagoa dos Gansos (C. lundellii Delponte var. borgei Gerloff \& Krieger e C. moniliforme var. moniliforme (Turpin) Ralfs). A
Lagoa do Cedro e a Lagoa Taquara apresentaram um táxon exclusivo cada (respectivamente, $C$. undulatum Corda ex Ralfs var. minutum Wittrock e C. tenue Archer) (tabela 2).

Tabela 2. Táxons de Cosmarium encontrados no perifíton de cinco lagoas do Distrito Federal (DF), Brasil e suas respectivas ocorrências nos diferentes períodos de coleta. Legenda:*: primeira citação para o DF; **: provável primeira citação para o Brasil; S6: seca de 2006; C8: chuva de 2008; S8: seca de 2008; C9: chuva de 2009.

Table 2. Taxa of Cosmarium in the periphyton of five lagoons in the Federal District (FD), Brazil and their respective occurrence in the different sampling periods. Legend: *: first citation for the FD; **: probable first citation for Brazil; S6: 2006 dry season; C8: 2008 rainy season; S8: 2008 dry season; C9: 2009 rainy season.

\begin{tabular}{|c|c|c|c|c|c|c|c|c|c|c|c|c|c|c|c|c|c|}
\hline \multirow[t]{2}{*}{ Táxons } & \multicolumn{3}{|c|}{$\begin{array}{l}\text { Lagoa } \\
\text { Bonita }\end{array}$} & \multicolumn{4}{|c|}{$\begin{array}{l}\text { Lagoa Joaquim } \\
\text { Medeiros }\end{array}$} & \multicolumn{4}{|c|}{$\begin{array}{l}\text { Lagoa do } \\
\text { Cedro }\end{array}$} & \multicolumn{2}{|c|}{$\begin{array}{l}\text { Lagoa } \\
\text { Taquara }\end{array}$} & & \multicolumn{3}{|c|}{$\begin{array}{c}\text { Lagoa dos } \\
\text { Gansos }\end{array}$} \\
\hline & S6 & C8 & C9 & S6 & $\mathrm{C} 8$ & S8 & C9 & S6 & $\mathrm{C} 8$ & S8 & C9 & S6 C & C8 & S8 S6 & $\begin{array}{ll}6 & \mathrm{C} 8\end{array}$ & S8 & C9 \\
\hline $\begin{array}{l}\text { * C. abbreviatum Raciborski var. minus } \\
\text { (West \& West) Krieger \& Gerloff }\end{array}$ & $\mathrm{x}$ & $\mathrm{x}$ & $\mathrm{x}$ & & $\mathrm{x}$ & & & $\mathrm{x}$ & & $\mathrm{x}$ & $\mathrm{x}$ & & & & & $\mathrm{x}$ & $\mathrm{x}$ \\
\hline $\begin{array}{l}* * \text { C. angulosum Brébisson var. } \\
\text { angulosum f. angulosum }\end{array}$ & $\mathrm{x}$ & $\mathrm{x}$ & $\mathrm{x}$ & & $\mathrm{x}$ & $\mathrm{x}$ & & & & & & & & & & $\mathrm{x}$ & \\
\hline * C. bipunctatum Börgensen & $\mathrm{x}$ & $\mathrm{x}$ & & $\mathrm{x}$ & $\mathrm{x}$ & $\mathrm{x}$ & & $\mathrm{x}$ & & & & & $\mathrm{x}$ & & & & \\
\hline $\begin{array}{l}\text { * C. botrytis var. botrytis Menegh. ex } \\
\text { Ralfs }\end{array}$ & $\mathrm{x}$ & $\mathrm{x}$ & $\mathrm{x}$ & $\mathrm{x}$ & $\mathrm{x}$ & $\mathrm{x}$ & & & & & & & & & $\mathrm{x}$ & & $\mathrm{x}$ \\
\hline $\begin{array}{l}\text { C. contractum Kirchner var. minutum } \\
\text { (Delponte) West \& West }\end{array}$ & & $\mathrm{x}$ & & & & & & $\mathrm{x}$ & & & & & & & & & \\
\hline $\begin{array}{l}\text { ** C. contractum Kirchner var. ornatum } \\
\text { Lagerheim }\end{array}$ & $\mathrm{x}$ & & $\mathrm{x}$ & & & & & $\mathrm{x}$ & & $\mathrm{x}$ & & & & & & & \\
\hline $\begin{array}{l}\text { C. denticulatum Borge var. ovale } \\
\text { Grönblad }\end{array}$ & $\mathrm{x}$ & $\mathrm{x}$ & & & & & & & & & & & & & & & \\
\hline * C. $\begin{array}{l}\text { denticulatum Borge var. } \\
\text { triangulare Grönblad }\end{array}$ & $\mathrm{x}$ & & $\mathrm{x}$ & & & & & & & & & & & & & & \\
\hline $\begin{array}{l}\text { **C. excavatum Nordstedt var. } \\
\text { duplo-maius (Wille) Förster }\end{array}$ & $\mathrm{x}$ & $\mathrm{x}$ & $\mathrm{x}$ & $\mathrm{x}$ & $\mathrm{x}$ & $\mathrm{x}$ & $\mathrm{x}$ & & & & & $\mathrm{x}$ & & $\mathrm{x}$ & $\mathrm{x}$ & & $\mathrm{x}$ \\
\hline $\begin{array}{l}\text { * C. exiguum Archer var. exiguum f. } \\
\text { exiguum }\end{array}$ & & $\mathrm{x}$ & & & & & & & & & & & & & & & \\
\hline C. furcatum Förster & & $\mathrm{x}$ & & & & $\mathrm{x}$ & & & & & & & & $\mathrm{x}$ & $\mathrm{x}$ & & \\
\hline C. horridum Borge & $\mathrm{x}$ & $\mathrm{x}$ & $\mathrm{x}$ & $\mathrm{x}$ & & & & & & & & & & & & & \\
\hline $\begin{array}{l}\text { * C. laeve Rabenhorst var. acervatum } \\
\text { Förster }\end{array}$ & $\mathrm{x}$ & $\mathrm{x}$ & & & & & & & & & & & & & & & \\
\hline $\begin{array}{l}\text { C. lagoense var. amoebum Förster } \\
\& \text { Eckert }\end{array}$ & & & $\mathrm{x}$ & & & & & $\mathrm{x}$ & & & $\mathrm{x}$ & & & & & & \\
\hline $\begin{array}{l}\text { * C. lundellii Delponte var. borgei } \\
\text { Gerloff \& Krieger }\end{array}$ & & & & & & & & & & & & & & $\mathrm{x}$ & $\mathrm{x}$ & & \\
\hline $\begin{array}{l}\text { C. moniliforme var. moniliforme } \\
\text { (Turpin) Ralfs }\end{array}$ & & & & & & & & & & & & & & $\mathrm{x}$ & x & & \\
\hline $\begin{array}{l}\text { **C. moniliforme (Turpin) Ralfs var. } \\
\text { ellipticum (Lagerheim) Krieger } \\
\text { \& Gerloff }\end{array}$ & & $\mathrm{x}$ & & $\mathrm{x}$ & $\mathrm{x}$ & $\mathrm{x}$ & & & & & & & & & & & \\
\hline $\begin{array}{c}\text { * C. moniliforme (Turpin) Ralfs f. } \\
\text { elongatum West \& West }\end{array}$ & $\mathrm{x}$ & $\mathrm{x}$ & & & & & & & & & & & & $\mathrm{x}$ & 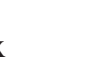 & & \\
\hline
\end{tabular}


Tabela 2 (continuação)

\begin{tabular}{|c|c|c|c|c|c|c|c|c|c|c|c|c|c|c|c|c|c|c|}
\hline \multirow[t]{2}{*}{ Táxons } & \multicolumn{3}{|c|}{$\begin{array}{l}\text { Lagoa } \\
\text { Bonita }\end{array}$} & \multicolumn{4}{|c|}{$\begin{array}{l}\text { Lagoa Joaquim } \\
\text { Medeiros }\end{array}$} & \multicolumn{4}{|c|}{$\begin{array}{l}\text { Lagoa do } \\
\text { Cedro }\end{array}$} & \multicolumn{3}{|c|}{$\begin{array}{l}\text { Lagoa } \\
\text { Taquara }\end{array}$} & \multicolumn{4}{|c|}{$\begin{array}{l}\text { Lagoa dos } \\
\text { Gansos }\end{array}$} \\
\hline & S6 & C8 & C9 & S6 & C8 & S8 & C9 & S6 & $\mathrm{C} 8$ & S8 & C9 & S6 & C8 & S8 & S6 & $\mathrm{C} 8$ & S8 & C9 \\
\hline $\begin{array}{l}\text { C. obsoletum (Hantzsch) Reinsch var. } \\
\text { obsoletum }\end{array}$ & & $\mathrm{x}$ & $\mathrm{x}$ & & & & & & & & & & & & $x$ & & & \\
\hline $\begin{array}{l}\text { * C. ocellatum Eichler \& Gutwinski } \\
\text { var. ocellatum }\end{array}$ & $\mathrm{x}$ & $\mathrm{x}$ & & & $x$ & & & $\mathrm{x}$ & & $\mathrm{x}$ & & & & & & & & \\
\hline $\begin{array}{l}\text { * C. ocellatum Eichler \& Gutwinski } \\
\text { var. brasiliense Förster }\end{array}$ & & $x$ & & & & & & & & & & & & & & & & \\
\hline $\begin{array}{l}\text { C. ordinatum (Börgesen) West \& } \\
\text { West var. ordinatum f. ordinatum }\end{array}$ & & $\mathrm{x}$ & $\mathrm{x}$ & & & & & & & & & & & & & & & \\
\hline $\begin{array}{l}* * C . \text { pericymatium var. pericymatium } \\
\text { Nordstedt }\end{array}$ & & $\mathrm{x}$ & & & $\mathrm{x}$ & & & & & & & & & & & & & \\
\hline $\begin{array}{l}\text { * C.phaseolus Brébisson var. phaseolus } \\
\text { f. minus Boldt }\end{array}$ & & & & $\mathrm{x}$ & & & & $\mathrm{x}$ & & & & & $x$ & & & & & \\
\hline $\begin{array}{l}\text { * C. polymorphum Nordstedt var. } \\
\text { groenbladii Förster }\end{array}$ & $\mathrm{x}$ & & $\mathrm{x}$ & & & & & & & & & & $\mathrm{x}$ & & $\mathrm{x}$ & & & \\
\hline $\begin{array}{l}* * \text { C. praecisum Borge var. suecicum } \\
\text { (Borge) Krieger \& Gerloff x } 962\end{array}$ & $\mathrm{x}$ & $\mathrm{x}$ & & & & & & $\mathrm{x}$ & & & & & & & & & & \\
\hline $\begin{array}{c}\text { ** Cosmarium pseudoconnatum var. } \\
\text { pluriradians } \text { Scott \& Grönblad }\end{array}$ & & $\mathrm{x}$ & & & $\mathrm{x}$ & $\mathrm{x}$ & $\mathrm{x}$ & & & & & & & & $x$ & & & \\
\hline $\begin{array}{l}\text { C. pseudopyramidatum Lundell var. } \\
\text { pseudopyramidatum }\end{array}$ & $\mathrm{x}$ & $\mathrm{x}$ & $\mathrm{x}$ & $\mathrm{x}$ & $\mathrm{x}$ & $\mathrm{x}$ & $\mathrm{x}$ & $\mathrm{x}$ & $\mathrm{x}$ & $\mathrm{x}$ & $\mathrm{x}$ & $\mathrm{x}$ & $\mathrm{x}$ & $\mathrm{x}$ & $\mathrm{x}$ & $\mathrm{x}$ & $\mathrm{x}$ & $\mathrm{x}$ \\
\hline $\begin{array}{l}\text { * C. quadrifarium Lundell var. } \\
\text { quadrifarium f. quadrifarium }\end{array}$ & $\mathrm{x}$ & & & & $\mathrm{x}$ & & & & & & & & & & & & & \\
\hline $\begin{array}{l}\text { C. quadrum Lundell var. minus } \\
\text { Nordstedt }\end{array}$ & $\mathrm{x}$ & $\mathrm{x}$ & $\mathrm{x}$ & & $\mathrm{x}$ & & & $\mathrm{x}$ & & & & $\mathrm{x}$ & & $\mathrm{x}$ & & & & \\
\hline * C. regnesii Reinsch var. regnesii & & & & $\mathrm{x}$ & & & & $\mathrm{x}$ & $\mathrm{x}$ & $\mathrm{x}$ & $\mathrm{x}$ & & & & & & & \\
\hline $\begin{array}{l}\text { * C. reniforme (Ralfs) Archer var. } \\
\text { reniforme f. reniforme }\end{array}$ & & & $\mathrm{x}$ & & & & & & & & $\mathrm{x}$ & & & & & & & \\
\hline $\begin{array}{l}\text { * C. sublobatum (Brébisson) Archer } \\
\text { var. brasiliense Borge }\end{array}$ & & & & & $\mathrm{x}$ & & & & & & & & & & & & & \\
\hline $\begin{array}{l}\text { * C. subspeciosum Nordstedt var. } \\
\text { subspeciosum }\end{array}$ & & & & $\mathrm{x}$ & & & & & & & & & & & & & & \\
\hline $\begin{array}{l}\text { *C. subspeciosum Nordstedt var. } \\
\text { subspeciosum f. brasiliense } \\
\text { Förster }\end{array}$ & & & & & & & & & & & & & $\mathrm{x}$ & & & $\mathrm{x}$ & & \\
\hline $\begin{array}{l}\text { * C. subtriordinatum West \& West var. } \\
\text { acervatum Förster }\end{array}$ & & $\mathrm{x}$ & $\mathrm{x}$ & & & & & $\mathrm{x}$ & & & & & & & & & & \\
\hline **C. tenue Archer & & & & & & & & & & & & & $\mathrm{x}$ & & & & & \\
\hline $\begin{array}{l}\text { * C. trilobulatum Reinsch var. } \\
\text { abscissum (Schmidle) Krieger } \\
\text { \& Gerloff }\end{array}$ & & $\mathrm{x}$ & & $\mathrm{x}$ & & & & & & & & & & $\mathrm{x}$ & $\mathrm{x}$ & $x$ & & \\
\hline $\begin{array}{c}\text { * } C . \text { undulatum Corda ex } \\
\text { Ralfs var. minutum Wittrock }\end{array}$ & & & & & & & & $\mathrm{x}$ & $\mathrm{x}$ & $\mathrm{x}$ & $\mathrm{x}$ & & & & & & & \\
\hline
\end{tabular}


Tabela 2 (continuação)

\begin{tabular}{|c|c|c|c|c|c|c|c|c|c|c|c|c|c|c|c|c|c|c|}
\hline \multirow[t]{2}{*}{ Táxons } & \multicolumn{3}{|c|}{$\begin{array}{l}\text { Lagoa } \\
\text { Bonita }\end{array}$} & \multicolumn{4}{|c|}{$\begin{array}{l}\text { Lagoa Joaquim } \\
\text { Medeiros }\end{array}$} & \multicolumn{4}{|c|}{$\begin{array}{l}\text { Lagoa do } \\
\text { Cedro }\end{array}$} & \multicolumn{3}{|c|}{$\begin{array}{c}\text { Lagoa } \\
\text { Taquara }\end{array}$} & \multicolumn{4}{|c|}{$\begin{array}{l}\text { Lagoa dos } \\
\text { Gansos }\end{array}$} \\
\hline & S6 & $\mathrm{C} 8$ & C9 & S6 & $\mathrm{C} 8$ & S8 & $\mathrm{C} 9$ & S6 & $\mathrm{C} 8$ & S8 & C9 & S6 & $\mathrm{C} 8$ & S8 & S6 & $\mathrm{C} 8$ & & $\mathrm{C} 9$ \\
\hline $\begin{array}{l}\text { * Cosmarium vitiosum Scott \& } \\
\text { Gröenblad }\end{array}$ & $\mathrm{x}$ & & $\mathrm{x}$ & & & & & & & & & & & & & & & \\
\hline Cosmarium sp. 1 & & & & & & & & $\mathrm{x}$ & $\mathrm{x}$ & & & & & & $\mathrm{x}$ & & & \\
\hline Cosmarium sp. 2 & $\mathrm{x}$ & $\mathrm{x}$ & $\mathrm{x}$ & & & & & & & & $\mathrm{x}$ & & & & & & & \\
\hline TOTAL DE TÁXONS & 19 & 25 & 17 & 10 & 13 & 8 & 3 & 14 & 4 & 6 & 7 & 3 & 6 & 4 & 11 & 4 & 4 & 4 \\
\hline
\end{tabular}

Chave artificial para identificação das espécies, variedades e formas encontradas

1. Parede lisa, pontuada, ou apresentando apenas escrobiculações ou espessamentos discretos

2. Célula com comprimento $>80 \mu \mathrm{m}$

C. pseudoconnatum var. pluriradians

2. Célula com comprimento $<80 \mu \mathrm{m}$

3. Célula com comprimento $<20 \mu \mathrm{m}$

4. Presença de uma pequena mamila na face ventral da semicélula

5. Célula com comprimento em torno de $10 \mu \mathrm{m}$ C. praecisum var. suecicum

5. Célula com comprimento em torno de $20 \mu \mathrm{m}$ C. phaseolus var. phaseolus f. minus

4. Ausência de mamilas na face ventral da semicélula

6. Semicélulas elipsóides

C. tenue var. tenue

6. Semicélulas trapeziformes ou subretangulares

7. Célula tão comprida quanto larga C. abbreviatum var. minus

7. Célula mais comprida do que larga

8. Semicélulas com margens laterais tendendo a retas .... C. angulosum var. angulosum f. angulosum

8. Semicélulas com lobos basais arredondados bem definidos ........... C. sublobatum var. brasiliense

3. Célula com comprimento $>20 \mu \mathrm{m}$

9. Semicélulas circulares, semicirculares ou elipsóides

10. Dois pirenóides por semicélula

11. Presença de espessamentos no ângulo inferior das semicélulas C. obsoletum

11. Ausência de espessamento no ângulo inferior das semicélulas C. lundelli var. borgei

10. Um pirenóide por semicélula

12. Seno fechado . C. laeve var. acervatum

12. Seno aberto

13. Seno aberto em "U" C. contractum var. ornatum 13. Seno aberto em "V"

14. Célula com comprimento $>35 \mu \mathrm{m}$

15. Razão comprimento/largura $<2$ C. moniliforme var. ellipticum

15. Razão comprimento/largura $>2$ C. moniliforme f. elongatum

14. Célula com comprimento $<35 \mu \mathrm{m}$

16. Semicélulas circulares C. moniliforme var. moniliforme 16. Semicélulas elipsóides ou subcirculares C. contractum var. minutum

9. Semicélulas com outros formatos

17. Semicélulas trapeziformes, subtriangulares ou semicirculares

18. Semicélulas sem escrobiculação central ... C. trilobulatum var. abscissum

18. Semicélulas com escrobiculação central

19. Semicélulas subtriangulares, com parede lisa C. ocellatum var. ocellatum

19. Semicélulas semicirculares, com parede pontuada C. ocellatum var. brasiliense 
17. Semicélulas piramidal-truncadas ou subquadrangulares
20. Célula com comprimento $>50 \mu \mathrm{m}$ C. pseudopyramidatum var. pseudopyramidatum
20. Célula com comprimento $<35 \mu \mathrm{m}$ C. exiguum

1. Parede com margem crenulada e/ou com granulação proeminente

21. Célula com comprimento $>100 \mu \mathrm{m}$

22. Razão comprimento/largura $>1,4$ C. denticulatum var. ovale

22. Razão comprimento/largura $<1,4$ C. denticulatum var. triangulare

21. Células com comprimento $<100 \mu \mathrm{m}$

23. Razão comprimento/largura até 1,1

24. Célula com comprimento $<20 \mu \mathrm{m}$

25. Semicélulas com espinhos furcados nas margens C. furcatum

25. Semicélulas sem espinhos, apenas com grânulos C. regnesii var. regnesii

24. Célula com comprimento $>20 \mu \mathrm{m}$

26. Célula apresentando espinhos conspícuos de até $13 \mu \mathrm{m}$ C. horridum

26. Célula com espinhos curtos ou apenas com grânulos ou verrugas, sem espinhos

27. Célula com espinhos

C. lagoense var. amoebum

27. Célula com grânulos ou verrugas

28. Célula ornada predominantemente com verrugas

29. Semicélulas oblongas, com verrugas dispostas em séries verticais

C. ordinatum var. ordinatum f. ordinatum

29. Semicélulas trapeziformes, com verrugas distribuídas irregularmente nas margens, formando um arranjo circular na face ventral

C. subtriordinatum var. acervatum

28. Célula ornada predominante com grânulos

30. Semicélulas apresentando um conjunto de verrugas na sua face ventral

C. bipunctatum

30. Semicélulas com granulação uniforme

31. Semicélulas subretangulares

C. quadrum var. minus

31. Semicélulas trapeziformes

Cosmarium sp. 1

23. Razão comprimento/largura $\geq 1,2$

32. Semicélulas reniformes ou oblongas

33. Semicélulas reniformes C. reniforme var. reniforme f. reniforme

33. Semicélulas oblongas Cosmarium sp. 2

32. Semicélulas com outros formatos

34. Célula com seno aberto

35. Célula com grânulos conspícuos, distribuídos uniformemente

C. excavatum var. duplo-maius

35. Célula com margem crenulada, sem grânulos C. pericymatium var. pericymatium

34. Célula com seno fechado

36. Célula com comprimento $<35 \mu \mathrm{m}$

37. Semicélulas com margem crenulada, apresentando dois grânulos destacados

na região subapical e central

C. polymorphum var. groenbladii

37. Semicélulas com margem ondulada, sem grânulos diferenciados

36. Célula com comprimento $>35 \mu \mathrm{m}$

38. Célula com granulação uniforme

C. undulatum var. minutum

38. Célula com granulação não uniforme

39. Margens apresentando dentículos .

C. botrytis var. botrytis

39. Margens sem dentículos

40. Margens com verrugas truncadas 


\section{Margens sem verrugas truncadas}

C. quadrifarium var. quadrifarium $\mathrm{f}$. quadrifarium

41. Semicélulas apresentando, em sua face ventral, cinco séries

verticais de grânulos, e logo abaixo uma série vertical

Cosmarium subspeciosum var. subspeciosum $\mathrm{f}$. brasiliense

41. Semicélulas sem o padrão de ornamentação anterior

Cosmarium subspeciosum var. subspeciosum

* Cosmarium abbreviatum Raciborski var. minus (West \& West) Krieger \& Gerloff, Die Gattung Cosmarium 3/4, p. 242; 1965, 2. pl. 42, fig. 18. 1969. Figuras 2-4

Células pequenas, tão compridas quanto largas; constrição mediana profunda, seno fechado, semicélulas retangulares a trapeziformes; ângulos basais arredondados, ápice truncado; parede celular lisa; vista apical elíptica; cloroplasto axial, com um pirenóide por semicélula. Compr. 8-12 $\mu \mathrm{m}$; larg. 8-12 $\mu \mathrm{m}$; istmo 4-6 $\mu \mathrm{m}$.

Distribuição geográfica: Cosmopolita (Prescott et al. 1981). Brasil: São Paulo (Araújo \& Bicudo 2006), Goiás (Felisberto \& Rodrigues 2004), Paraná (Felisberto \& Rodrigues 2008, 2010a, b).

Material examinado: BRASIL. Distrito Federal: Brasília: Lagoa Bonita, 25-VIII-2006, L.M.B. Estrela \& B.M. Fonseca s.n. (UB1794); idem, 27-V-2008, L.M.B. Estrela \& B.M. Fonseca s.n. (UB1795); idem, 10-III-2009, L.M.B. Estrela \& B.M. Fonseca s.n. (UB1796); Lagoa Joaquim Medeiros, 25-IV-2008, L.M.B. Estrela \& B.M. Fonseca s.n. (UB1789); Lagoa do Cedro, 19-IX-2006, L.M.B. Estrela \& B.M. Fonseca s.n. (UB1779); idem, 19-IX-2008, L.M.B. Estrela \& B.M. Fonseca s.n. (UB1781); idem, 3-III-2009, L.M.B. Estrela \& B.M. Fonseca s.n. (UB1782); Lagoa dos Gansos, 5-IX-2008, L.M.B. Estrela \& B.M. Fonseca s.n. (UB1785); idem, 20-III-2009, L.M.B. Estrela \& B.M. Fonseca s.n. (UB1786).

C. abbreviatum pode apresentar grande variedade morfológica (Bicudo 1988), o que, de fato, foi confirmado no presente estudo. A var. minus difere da típica pelo menor tamanho, embora se observe alguma sobreposição de medidas (compr. 10-25 $\mu \mathrm{m}$; larg. 10-29 $\mu \mathrm{m}$ na variedade típica, segundo Prescott et al. 1981). Táxons muito próximos e que merecem uma revisão são $C$. angulosum Brébisson (ver comentários adiante) e C. minimum West \& West.
** Cosmarium angulosum Brébisson var. angulosum f. angulosum, Mém. Soc. Impér. Nat. Cherbourg 4: 127. pl. 1, fig. 17. 1856.

Figuras 5-7

Células pequenas, 1,2-1,5 vezes mais compridas que largas; constrição mediana profunda, seno fechado, semicélulas trapeziformes a subretangulares; ângulos basais obtuso arredondados, margens laterais inferiores paralelas ou ligeiramente convexas, ápice truncado; parede celular lisa; cloroplasto axial, com um pirenóide por semicélula; vista apical elíptica. Compr. 12-15 $\mu \mathrm{m}$; larg. 9-11 $\mu \mathrm{m}$; istmo 3-5 $\mu \mathrm{m}$.

Distribuição geográfica: Cosmopolita (Prescott et al. 1981). Não foram encontradas citações para o Brasil.

Material examinado: BRASIL. Distrito Federal: Brasília: Lagoa Bonita, 25-VIII-2006, L.M.B. Estrela \& B.M. Fonseca s.n. (UB1794); idem, 27-V-2008, L.M.B. Estrela \& B.M. Fonseca s.n. (UB1795); idem, 10-III-2009, L.M.B. Estrela \& B.M. Fonseca s.n. (UB1796); Lagoa Joaquim Medeiros, 25-IV-2008, L.M.B. Estrela \& B.M. Fonseca s.n. (UB1789); idem, 22-VIII-2008, L.M.B. Estrela \& B.M. Fonseca s.n. (UB1788); Lagoa dos Gansos, 5-IX-2008, L.M.B. Estrela \& B.M. Fonseca s.n. (UB1785).

Segundo Prescott et al. (1981), C. angulosum é uma espécie extremamente variável. Esses autores citaram pelo menos quatro variedades, em geral com diferenças no tamanho e no formato das semicélulas. Bicudo (1988) apontou sobreposição com C. abbreviatum. No presente estudo, C. angulosum foi separado de C. abbreviatum pela maior razão comprimento/largura. Nas amostras da Lagoa Joaquim Medeiros, foram observados indivíduos unidos por um tubo de mucilagem (figura 7).

* Cosmarium bipunctatum Börgensen, Vidensk. Medd. Naturh. Foren. Kjöbenhavn 1890: 40, pl. 4, fig. 33. 1890.

Figuras 8-10 
Células pequenas, tão longas quanto largas ou ligeiramente mais longas; constrição mediana profunda, seno fechado, semicélulas oblongo-trapeziformes, margens laterais convexas, margem apical amplamente truncada, ângulos apical e basal arredondados; parede celular granulada, com um conjunto de verrugas na região central das semicélulas; cloroplasto axial, um pirenóide por semicélula; vista apical elíptica. Compr. 18-19 $\mu \mathrm{m}$; larg. 16-17 $\mu \mathrm{m}$; istmo 4-6 $\mu \mathrm{m}$.

Distribuição geográfica: Cosmopolita (Prescott et al. 1981). Brasil: São Paulo (Borge 1918), Mato Grosso (Borge 1924).

Material examinado: BRASIL. Distrito Federal: Brasília: Lagoa Bonita, 25-VIII-2006, L.M.B. Estrela \& B.M. Fonseca s.n. (UB1794); idem, 27-V-2008, L.M.B. Estrela \& B.M. Fonseca s.n. (UB1795); Lagoa Joaquim Medeiros, 8-VIII-2006, L.M.B. Estrela \& B.M. Fonseca s.n. (UB1787); idem, 25-IV-2008, L.M.B. Estrela \& B.M. Fonseca s.n. (UB1789); idem, 22-VIII-2008, L.M.B. Estrela \& B.M. Fonseca s.n. (UB1788); Lagoa do Cedro, 19-IX-2006, L.M.B. Estrela \& B.M. Fonseca s.n. (UB1779); Lagoa Taquara, 6-V-2008, L.M.B. Estrela \& B.M. Fonseca s.n. (UB1792).

Táxons próximos são $C$. punctulatum Brébisson e C. orthosthicum Lundell. Os mesmos, porém, não apresentam verrugas maiores no centro da semicélula. Outro táxon semelhante é C. spharelostichum Nordstedt f. bituberculatum Förster. Porém tal táxon apresenta verrugas logo abaixo do ápice, e não na região central da semicélula. Além disso, C. spharelostichum, segundo Prescott et al. (1981), apresenta semicélulas com base mais achatada, e ângulos subretangulares. Os indivíduos observados no presente estudo, porém, apresentaram células oblongotrapeziformes, com ângulos bem arredondados. Vale comentar ainda que estão um pouco abaixo das medidas mencionadas por Prescott et al. (1981) (compr. 20-25 $\mu \mathrm{m}$; larg. 19-20 $\mu \mathrm{m}$ ).

* Cosmarium botrytis var. botrytis Meneghini ex Ralfs, Brit. Desm., p. 99, pl. 16, fig. 1. 1848. Figuras 11-13

Células grandes, 1,4-1,5 vezes mais longas que largas; constrição mediana profunda, seno fechado e dilatado na extremidade; semicélula oval piramidal, ângulos arredondados, margem lateral convexa; parede celular granulada, semicélulas com grânulos pequenos dispostos de forma uniforme e definida, ápices truncados; cloroplasto axial, um pirenóide por semicélula; vista apical elíptica. Compr. 67-70 $\mu \mathrm{m}$; larg. 45-50 $\mu \mathrm{m}$; istmo $15-20 \mu \mathrm{m}$.

Distribuição geográfica: Cosmopolita. Brasil: Rio de Janeiro (Sophia 1999), Rio Grande do Sul (Sophia et al. 2005).

Material examinado: BRASIL. Distrito FederAl: Brasília: Lagoa Bonita, 25-VIII-2006, L.M.B. Estrela \& B.M. Fonseca s.n. (UB1794); idem, 27-V-2008, L.M.B. Estrela \& B.M. Fonseca s.n. (UB1795); idem, 10-III-2009, L.M.B. Estrela \& B.M. Fonseca s.n. (UB1796); Lagoa Joaquim Medeiros, 8-VIII-2006, L.M.B. Estrela \& B.M. Fonseca s.n. (UB1787); idem, 25-IV-2008, L.M.B. Estrela \& B.M. Fonseca s.n. (UB1789); idem, 22-VIII-2008, L.M.B. Estrela \& B.M. Fonseca s.n. (UB1788); Lagoa dos Gansos, 2-V-2008, L.M.B. Estrela \& B.M. Fonseca s.n. (UB1784); idem, 20-III-2009, L.M.B. Estrela \& B.M. Fonseca s.n. (UB1786).

Segundo Prescott et al. (1981), C. botrytis é extremamente variável em forma da semicélula e na disposição dos grânulos. O achatamento nos ápices foi bem típico entre os indivíduos encontrados no presente estudo.

\section{Cosmarium contractum Kirchner var. minutum}

(Delponte) West \& West, Monograph. 2: 173, pl. 61, figs. 30-33. 1905.

\section{Figura 14}

Células médias, 1,7-1,9 vezes mais longas que largas; constrição mediana profunda, seno amplamente aberto, acutangular; semicélulas elípticas; margem lateral lisa, parede celular lisa a finamente pontuada; cloroplasto axial, com um pirenóide por semicélula; vista apical elíptica, vista lateral circular. Compr. 25-27 $\mu \mathrm{m}$; larg. 13-16 $\mu \mathrm{m}$; istmo 4-5 $\mu \mathrm{m}$.

Distribuição geográfica: Cosmopolita (Prescott et al. 1981). Brasil: Amazônia (Förster 1974), São Paulo (Araújo \& Bicudo 2006), Distrito Federal (Mendonça-Galvão 2005).

Material examinado: BRASIL. Distrito Federal: Brasília: Lagoa Bonita, 27-V-2008, L.M.B. Estrela \& B.M. Fonseca s.n. (UB1795); Lagoa do Cedro, 9-IX-2006, L.M.B. Estrela \& B.M. Fonseca s.n. (UB1779).

C. contractum é uma espécie relativamente comum e possui vários táxons infra-específicos, os 
quais podem variar em relação aos seguintes aspectos: formatos de semicélulas, dimensões, abertura do istmo (ora em "U", ora em "V"), presença ou não de espessamento na parede (Prescott et al. 1981). Uma característica geral da população analisada no presente estudo foram as dimensões relativamente inferiores às da variedade típica, com comprimento celular sempre $<30 \mu \mathrm{m}$, além de razão comprimento/largura próxima a dois (a variedade típica, segundo Prescott et al. (1981), possui razão comprimento/largura entre 1,3 a 1,5; compr. 30-54 $\mu \mathrm{m}$; larg. 17-34 $\mu \mathrm{m}$ ). No Distrito Federal, a variedade típica foi registrada para o Lago Paranoá (Mendonça-Galvão 2005, Philomeno 2007) e para a Lagoa Bonita (Gomes 2007), nesse último caso com identificação a conferatum. Vários trabalhos têm citado $C$. contractum var. contractum com dimensões que se enquadram na variedade minutum (e.g. Silva \& Cecy 2004, Felisberto \& Rodrigues 2008). A menos que os limites métricos da variedade típica sejam revistos, preferiu-se, no presente estudo, manter a variedade minutum.

** Cosmarium contractum Kirchner var. ornatum Lagerheim, Öfv. Kongl. Vet.-Akad. Förhandl. 42(7): 240, pl. 27, fig. 14. 1886.

Figura 15

Células médias, aproximadamente duas vezes mais longas que largas; constrição mediana profunda, seno amplamente aberto; semicélulas ligeiramente elipsóides; margem lateral lisa, parede celular lisa a finamente pontuada, com uma região mediana espessada e amarronzada; vista apical ligeiramente elíptica. Compr. 21-26 $\mu \mathrm{m}$; larg. 11-13 $\mu \mathrm{m}$; istmo 5-6 $\mu \mathrm{m}$.

Distribuição geográfica: Segundo Prescott et al. (1981), a var. ornatum estaria restrita aos Estados Unidos. Não foram encontradas citações dessa variedade para o Brasil.

Material examinado: BRASIL. Distrito Federal: Brasília: Lagoa Bonita, 25-VIII-2006, L.M.B. Estrela \& B.M. Fonseca s.n. (UB1794); idem, 10-III-2009, L.M.B. Estrela \& B.M. Fonseca s.n. (UB1796); Lagoa do Cedro, 9-IX-2006, L.M.B. Estrela \& B.M. Fonseca s.n. (UB1779); idem, 19-IX-2008, L.M.B. Estrela \& B.M. Fonseca s.n. (UB1781).

Segundo Prescott et al. (1981), essa variedade difere da típica pela razão comprimento/largura em torno de dois e pela presença de espessamento na parede celular. Vale ressaltar que a população analisada apresentou dimensões bem menores do que a mencionada na literatura (44-47 $\mu \mathrm{m}$ de compr., segundo Prescott et al. 1981). Ainda assim, preferiu-se separá-la de $C$. contractum var. minutum pelas diferenças nas semicélulas e na abertura do istmo. Prescott et al. (1981) citaram C. americanum Lagerheim com descrição e ilustrações muito parecidas com o material encontrado no presente estudo. Entretanto, tais autores reconheceram que essa espécie é rara e muito pouco conhecida. Até que haja uma melhor definição da mesma, os indivíduos encontrados aqui serão mantidos em $C$. contractum var. ornatum.

Cosmarium denticulatum Borge var. ovale Grönblad, Acta Soc. Sci. Fennicae, II, B, 2(6): 17, pl. 5, figs. 98-100. 1945.

Figura 16

Células grandes, 1,5 vezes mais longas que largas; constrição mediana profunda, seno fechado; semicélulas piramidais com os ápices ligeiramente truncados, ângulos arredondados, parede celular com dentículos proeminentes, menos evidentes na porção central da semicélula; cloroplasto axial, um pirenóide por semicélula; vista apical elíptica. Compr. 178-190 $\mu \mathrm{m}$; larg. 120-130 $\mu \mathrm{m}$; istmo $46-50 \mu \mathrm{m}$.

Distribuição geográfica: Américas do Sul e do Norte (Prescott et al. 1981). Brasil: Mato Grosso (Borge 1924, Camargo et al. 2009), São Paulo (Borge 1918), Pará (Grönblad 1945, Förster 1969), Amazonas (Lopes \& Bicudo 2003), Paraná (Bortolini et al. 2010), Distrito Federal, Lagoa Bonita (Gomes 2007).

Material examinado: BRASIL. Distrito Federal: Brasília: Lagoa Bonita, 25-VIII-2006, L.M.B. Estrela \& B.M. Fonseca s.n. (UB1794); idem, 27-V-2008, L.M.B. Estrela \& B.M. Fonseca s.n. (UB1795).

Segundo Grönblad (1945), C. denticulatum pode ser encontrado em ambientes brasileiros sob várias formas. Esse autor descreveu as variedades ovale (compr. 137-198 $\mu \mathrm{m}$ ), triangulare (compr. 144-167 $\mu \mathrm{m}$ ) e perspinosum (compr. 194-213 $\mu \mathrm{m}$ ), as quais se diferenciam pelo tamanho, formato das semicélulas e pela distribuição dos espinhos. Apenas a variedade perspinosum tem espinhos ao longo de toda célula; nas outras duas, a parte central de semicélula é lisa ou com espinhos esparsos. No presente estudo, foram observadas duas populações distintas: uma com células mais compridas (razão $c / l=1,5$ ) e seno 
fechado, e outra com células menores (razão c/l =1,1) e seno aberto, acutangular. Ambas aparentam ter espinhos mais esparsos no centro de semicélula. A primeira foi identificada aqui como $C$. denticulatum var. ovale; a segunda, como $C$. denticulatem var. triangulare.

* Cosmarium denticulatum Borge var. triangulare Grönblad, Acta Soc. Sci. Fennicae, II, B, 2(6): 17. pl. 5, figs. 101-102. 1945.

Figuras 17-18

Células grandes, aproximadamente 1,1 vezes mais longas que largas; constrição mediana profunda, seno acutangular; semicélula piramidal com ápices ligeiramente achatados, ângulos basais arredondados; parede celular com dentículos proeminentes; cloroplasto axial, um pirenóide por semicélula; vista apical elíptica. Compr. $155 \mu \mathrm{m}$; larg. $142 \mu \mathrm{m}$; istmo $40 \mu \mathrm{m}$.

Distribuição geográfica: Brasil: Pará (rio Amazonas) (Grönblad 1945, Förster 1969), Paraná (Bittencourt-Oliveira 1993 apud Bortolini et al. 2010).

Material examinado: BRASIL. Distrito Federal: Brasília: Lagoa Bonita, 25-VIII-2006, L.M.B. Estrela \& B.M. Fonseca s.n. (UB1794); idem, 10-III-2009, L.M.B. Estrela \& B.M. Fonseca s.n. (UB1796).

Aparentemente, tal táxon é menos comum do que a var. ovale. Essa variedade apresenta células mais triangulares e menor razão comprimento/largura quando comparada à variedade ovale (ver comentários em C. denticulatum var. ovale).

** Cosmarium excavatum Nordstedt var. duplo-maius (Wille) Förster, Nova Hedwigia 23 (2/3): 549, pl. 16, fig. 22. 1972.

Figura 19

Células grandes, 2,2 vezes mais longas do que largas; constrição mediana suave, seno raso e aberto; semicélulas oblongas, parede celular granulada, grânulos distribuídos de forma uniforme por toda a semicélula, formando séries verticais, 17-20 grânulos visíveis na margem lateral da semicélula; cloroplasto axial, um pirenóide por semicélula; vista apical circular. Compr. 36-39 $\mu \mathrm{m}$; larg. 16-18 $\mu \mathrm{m}$; istmo $14 \mu \mathrm{m}$.

Distribuição geográfica: Continente Americano, Europa (Prescott et al. 1981). Brasil: não foram encontradas citações desta variedade.

Material examinado: BRASIL. Distrito Federal: Brasília: Lagoa Bonita, 25-VIII-2006, L.M.B. Estrela
\& B.M. Fonseca s.n. (UB1794); idem, 27-V-2008, L.M.B. Estrela \& B.M. Fonseca s.n. (UB1795); idem, 10-III-2009, L.M.B. Estrela \& B.M. Fonseca s.n. (UB1796); Lagoa Joaquim Medeiros, 8-VIII-2006, L.M.B. Estrela \& B.M. Fonseca S.n. (UB1787); idem, 22-VIII-2008, L.M.B. Estrela \& B.M. Fonseca s.n. (UB1788); idem, 25-IV-2008, L.M.B. Estrela \& B.M. Fonseca s.n. (UB1789); idem, 10-III-2009, L.M.B. Estrela \& B.M. Fonseca s.n. (UB1790); Lagoa Taquara, 15-VIII-2006, L.M.B. Estrela \& B.M. Fonseca s.n. (UB1791); idem, 29-III-2009, L.M.B. Estrela \& B.M. Fonseca s.n. (UB1793); Lagoa dos Gansos, 8-VIII-2006, L.M.B. Estrela \& B.M. Fonseca s.n. (UB1783); idem, 2-V-2008, L.M.B. Estrela \& B.M. Fonseca s.n. (UB1784); idem, 20-III-2009, L.M.B. Estrela \& B.M. Fonseca s.n. (UB1786).

Segundo Prescott et al. (1981), essa variedade difere da típica por ser duas vezes maior, com dimensões de acordo com os indivíduos observados no presente estudo. Assemelha-se a $C$. amoenum Brébisson ex Ralfs e a C. simplicius (West \& West) Grönblad, diferindo dos mesmos por possuir seno mais aberto. No Brasil, a variedade típica já foi registrada em São Paulo (Börge 1918), Mato Grosso (Börge 1924), Amazonas (Lopes \& Bicudo 2003) e Paraná (Felisberto \& Rodrigues 2010a, b).

* Cosmarium exiguum Archer exiguum f. exiguum, Proc. Dublin Nat. Hist. Soc. 1864: 49, pl. 1, figs. 32, 33. 1864.

Figura 20

Células médias, 2,1 vezes mais longas que largas; constrição mediana profunda; semicélulas subquadráticas com ângulos arredondados, às vezes levemente subpiramidais; ápice achatado; cloroplasto axial, com um pirenóide por semicélula; semicélulas elípticas em vista lateral e apical. Compr. 23-29 $\mu \mathrm{m}$; larg. 11-14 $\mu \mathrm{m}$; istmo 4-5 $\mu \mathrm{m}$.

Distribuição geográfica: Cosmopolita (Prescott et al. 1981). Brasil: Pará (Förster 1969), Amazonas (Lopes \& Bicudo 2003), São Paulo (Araújo 2006).

Material examinado: BRASIL. Distrito Federal: Brasília: Lagoa Bonita, 27-V-2008, L.M.B. Estrela \& B.M. Fonseca s.n. (UB1795).

Os indivíduos analisados apresentaram variações no formato das semicélulas, um pouco menos quadráticas e mais piramidais que em algumas ilustrações da literatura (e.g., Prescott et al. 1981). 


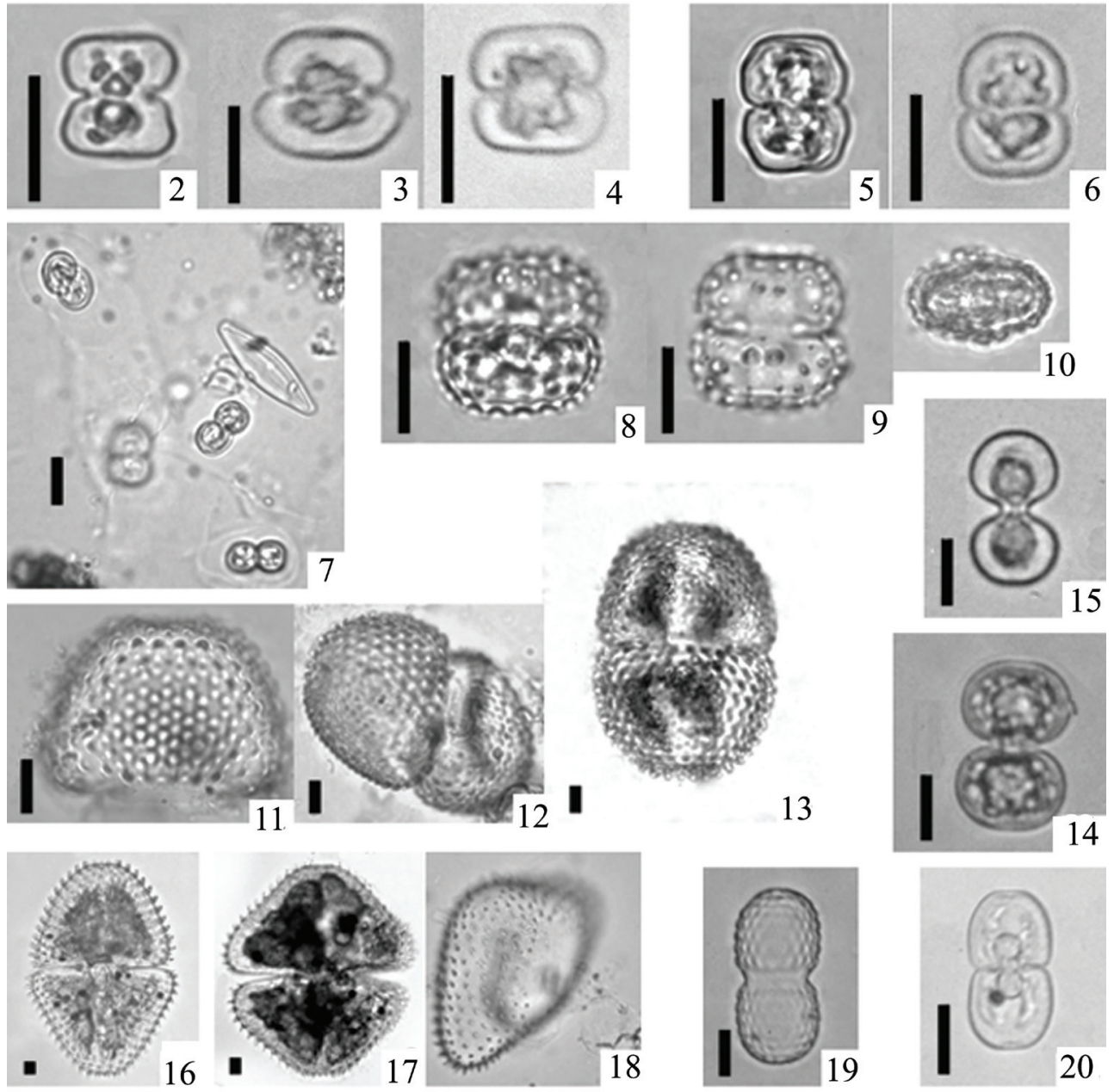

Figuras 2-20. 2-4. Cosmarium abbreviatum var. minus. 5-7. C. angulosum var. angulosum f. angulosum. 5-6. Variação morfológica intrapopulacional. 7. Tubos de mucilagem. 8-10. C. bipunctatum. 8-9. Vista frontal. 10. Vista apical. 11-13. C. botrytis var. botrytis. 14. C. contractum var. minutum. 15. C. contractum var. ornatum. 16. C. denticulatum var. ovale. 17-18. C. denticulatum var. triangulare. 17. Vista frontal. 18. Perspectiva da semicélula. 19. C. excavatum var. duplo-maius. 20. C. exiguum. (Barra da escala $=10 \mu \mathrm{m}$ ).

Figures 2-20. 2-4. Cosmarium abbreviatum var. minus. 5-7. C. angulosum var. angulosum f. angulosum. 5-6. Intrapopulation morphological variation. 7. Mucilaginous tubes. 8-10. C. bipunctatum. 8-9. Front view. 10. Apical view. 11-13. C. botrytis var. botrytis. 14. C. contractum var. minutum. 15. C. contractum var. ornatum. 16. C. denticulatum var. ovale. 17-18. C. denticulatum var. triangulare. 17. Front view. 18. Perspective of the semicell. 19. C. excavatum var. duplo-maius. 20. C. exiguum. (Scale bar $=10 \mu \mathrm{m})$.

Cosmarium furcatum Förster, Hydrobiologia 23 (3/4):

391. pl. 22, figs. 26-28. 1964.

Figura 21

Células pequenas, 1,1 vez mais longas que largas; constrição mediana profunda, seno amplamente aberto, ápice convexo; semicélula subtriangular, margem lateral crenulada, ângulos com espinhos furcados; parede celular granulada com grânulos espaçados e em série; vista apical elíptica. Compr. 16-17 $\mu \mathrm{m}$; larg. 14-17 $\mu \mathrm{m}$; istmo $8 \mu \mathrm{m}$.

Distribuição geográfica: Brasil: Goiás (Förster 1964),
Rio de Janeiro (Sophia 1999), Distrito Federal, Lagoa Bonita, (Leite 1990).

Material examinado: BRASIL. Distrito Federal: Brasília: Lagoa Bonita, 27-V-2008, L.M.B. Estrela \& B.M. Fonseca s.n. (UB1795); Lagoa Joaquim Medeiros, 22-VIII-2008, L.M.B. Estrela \& B.M. Fonseca s.n. (UB1788); Lagoa dos Gansos, 8-VIII-2006, L.M.B. Estrela \& B.M. Fonseca s.n. (UB1783).

Esse táxon foi descrito por Förster (1964) em amostras coletadas no Estado de Goiás. 
Cosmarium horridum Borge, Bihang Till K. Sv. Vet.-Akad. Handl. Band 24. Afd. III No. 12. 1899. Figura 22

Células grandes, tão longas quanto largas; constrição mediana profunda, seno aberto, margem basal côncava; semicélulas elipsóides, margem lateral com oito espinhos pontiagudos grandes (até $13 \mu \mathrm{m}$ ) e vários pequenos, presença de verrugas na parede celular; cloroplasto axial, com dois pirenóides por semicélula; vista apical elíptica com três espinhos visíveis em cada uma das duas extremidades da semicélula. Compr. 48-60 $\mu \mathrm{m}$; larg. 45-67 $\mu \mathrm{m}$; istmo 6-12 $\mu \mathrm{m}$.

Distribuição geográfica: Neotropical (Coesel et al. 1988). Brasil: Mato Grosso (Börge 1899), São Paulo (Börge 1918), Distrito Federal, Lagoa Bonita (Leite 1990, Gomes 2007).

Material examinado: BRASIL. Distrito Federal: Brasília: Lagoa Bonita, 25-VIII-2006, L.M.B. Estrela \& B.M. Fonseca s.n. (UB1794); idem, 27-V-2008, L.M.B. Estrela \& B.M. Fonseca s.n. (UB1795); idem, 10-III-2009, L.M.B. Estrela \& B.M. Fonseca s.n. (UB1796); Lagoa Joaquim Medeiros, 8-VIII-2006, L.M.B. Estrela \& B.M. Fonseca s.n. (UB1787).

A ilustração original apresenta semicélulas mais arredondadas e istmo fechado, linear. Entretanto, na literatura também é possível encontrar indivíduos com seno levemente aberto e número de espinhos variável (e.g., Coesel et al. 1988).

* Cosmarium laeve Rabenhorst var. acervatum Förster, Hydrobiologia 23 (3/4): 393, tab. 19, figs. 5-7. 1964.

Figuras 23-24

Células médias, 1,4-1,7 vezes mais longas do que largas, constrição mediana profunda, seno fechado, dilatado no ápice, margem lateral lisa, parede finamente pontuada; ápices arredondados com uma leve reentrância; semicélulas semicirculares; cloroplasto axial, um pirenóide por semicélula; vista apical elíptica. Compr. 22-29 $\mu \mathrm{m}$; larg. 13-21 $\mu \mathrm{m}$; istmo 5-6 $\mu \mathrm{m}$.

Distribuição geográfica: Brasil: Bahia (Förster 1964), Goiás (Felisberto \& Rodrigues 2004).

Material examinado: BRASIL. Distrito Federal: Brasília: Lagoa Bonita, 25-VIII-2006, L.M.B. Estrela \& B.M. Fonseca s.n. (UB1794); idem, 27-V-2008, L.M.B. Estrela \& B.M. Fonseca s.n. (UB1795).
Prescott et al. (1981) citaram pelo menos oito variedades de $C$. laeve. Förster (1964) descreveu a var. acervatum a partir de amostras da Bahia. Embora esse autor não tenha apresentado detalhes sobre as diferenças entre a var. acervatum e a variedade típica, mencionou semicélulas trapeziformes arredondadas, enquanto a descrição e ilustrações de Prescott et al. (1981), em geral, mostraram semicélulas com margens um pouco mais retas, angulares. A população analisada apresentou semicélulas amplamente arredondadas, de acordo com a descrição e ilustração original de Förster (1964).

Cosmarium lagoense Nordstedt var. amoebum Förster \& Eckert, in Förster 1964, Hydrobiologia 23 (3/4): 394. pl. 24, figs. 10-13. 1964.

Figuras 25-26

Células grandes, mais largas que longas ou tão longas quanto largas; constrição mediana profunda, seno fechado a levemente aberto nas extremidades, margem basal côncava; semicélulas elipsóides, estendidas lateralmente para formar um lobo convexo e com o ápice elevado, margem lateral com dentículos, presença de grânulos e espinhos proeminentes na margem lateral e apical da semicélula; cloroplasto axial, dois pirenóides por semicélula; vista apical elíptica. Compr. $40 \mu \mathrm{m}$; larg. $50 \mu \mathrm{m}$; istmo $12 \mu \mathrm{m}$.

Distribuição geográfica: Continente americano (Prescott et al. 1981). Brasil: Goiás (Förster 1964, Feliberto \& Rodrigues 2004), Amazonas (Förster 1974), Paraná (Felisberto \& Rodrigues 2010a, b), Mato Grosso (Camargo et al. 2009), Distrito Federal, Reservatório de Santa Maria (Cronberg 1977).

Material examinado: BRASIL. Distrito Federal: Brasília: Lagoa Bonita, 10-III-2009, L.M.B. Estrela \& B.M. Fonseca s.n. (UB1796); Lagoa do Cedro, 19-IX-2006, L.M.B. Estrela \& B.M. Fonseca s.n. (UB1779); idem, 3-III-2009, L.M.B. Estrela \& B.M. Fonseca s.n. (UB1782).

* Cosmarium lundellii Delponte var. borgei Gerloff \& Krieger, Die Gattung Cosmarium, 1: 3, pl. 1, fig. 6. 1962.

Figura 27

Células grandes, quase tão longas quanto largas; constrição mediana profunda, seno linear fechado; semicélulas sub-semicirculares, ângulos acuminado arredondados, margens amplamente convexas; parede 
celular pontuada, um cloroplasto axial por semicélula, estelóide, com quatro lamelas longitudinais, dois pirenóides grandes situados um ao lado do outro; vista apical rômbico-elíptica. Compr. 57-58 $\mu \mathrm{m}$; larg. $58 \mu \mathrm{m}$; istmo $20 \mu \mathrm{m}$.

Distribuição geográfica: Brasil: São Paulo (Araújo 2006).

Material examinado: BRASIL. Distrito Federal: Brasília: Lagoa dos Gansos, 8-VIII-2006, L.M.B. Estrela \& B.M. Fonseca s.n. (UB1783).

De acordo com Araújo (2006), a var. borgei foi descrita a partir de material coletado no Estado de São Paulo, caracterizando-se por apresentar tamanho menor em relação à variedade típica.

\section{Cosmarium moniliforme var. moniliforme (Turpin)}

Ralfs, Brit. Desm.: 107, pl. 17, fig. 6. 1848.

Figura 28

Células médias, 1,9 vezes mais longas que largas; constrição mediana profunda, seno amplamente aberto, acutangular; semicélulas circulares; margem lateral lisa, parede celular lisa a finamente pontuada; cloroplasto axial com lobos verticais; vista apical circular. Compr. $28 \mu \mathrm{m}$; larg. $15 \mu \mathrm{m}$; istmo $5 \mu \mathrm{m}$.

Distribuição geográfica: Cosmopolita (Prescott et al. 1981). Brasil: Minas Gerais, Rio Grande do Sul, Mato Grosso (Borge 1918); Paraná (Silva \& Cecy 2004); São Paulo (Araújo 2006); no Distrito Federal, citado para o Lago Paranoá (Mendonça-Galvão 2005) e para a Lagoa Bonita (Gomes 2007), nesse último caso com identificação a conferatum.

Material examinado: BRASIL. Distrito Federal: Brasília: Lagoa dos Gansos, 8-VIII-2006, L.M.B. Estrela \& B.M. Fonseca s.n. (UB1783).

Táxon semelhante a $C$. contractum Kirchner, do qual se diferencia pelas semicélulas nitidamente circulares e pelo cloroplasto axial lobulado.

** Cosmarium moniliforme (Turpin) Ralfs var. ellipticum (Lagerheim) Krieger \& Gerloff, Die Gattung Cosmarium 3/4: 338, pl. 54, fig. 5. 1969. Figura 29

Células grandes, 1,8 vezes mais longas que largas; constrição mediana moderadamente profunda, seno bastante aberto e acutangular; semicélulas circulares ou subcirculares; um cloroplasto axial em cada semicélula, com um pirenóide central e aproximadamente seis lobos verticais radiais; em vista lateral, semicélulas circulares ou subcirculares, muito semelhantes à vista frontal; em vista apical, célula circular. Compr. 45-50 $\mu \mathrm{m}$; larg. 26-28 $\mu \mathrm{m}$; istmo $13-14 \mu \mathrm{m}$.

Distribuição geográfica: Estados Unidos, Europa, Ásia, Austrália (Prescott et al. 1981). Não foram encontradas citações dessa variedade para o Brasil.

Material examinado: BRASIL. Distrito Federal: Brasília: Lagoa Bonita, 27-V-2008, L.M.B. Estrela \& B.M. Fonseca s.n. (UB1795); Lagoa Joaquim Medeiros, 8-VIII-2006, L.M.B. Estrela \& B.M. Fonseca s.n. (UB1787); idem, 25-IV-2008, L.M.B. Estrela \& B.M. Fonseca s.n. (UB1789); idem, 22-VIII-2008, L.M.B. Estrela \& B.M. Fonseca s.n. (UB1788).

Os indivíduos encontrados no presente estudo apresentaram dimensões maiores do que a variedade típica (compr. 16-41 $\mu \mathrm{m}$ e larg. 11-24 $\mu \mathrm{m}$, segundo Prescott et al. 1981), e células levemente elípticas, lembrando um pouco $C$. contractum Kirchner mas com o cloroplasto típico de C. moniliforme. As medidas e a descrição estão de acordo com a var. ellipticum citada por Prescott et al. (1981).

* Cosmarium moniliforme (Turpin) Ralfs f. elongatum West\& West, Linn. Soc. Jour. Bot.33:311, pl. 17, fig. 14. 1908.

Figuras 30-31

Células grandes, 2,2-2,3 vezes mais longas que largas; constrição mediana profunda, seno bastante aberto e acutangular; semicélulas arredondadas ou subquadrangulares; um cloroplasto axial lobulado em cada semicélula, com um pirenóide central; vista apical circular. Compr. 50-77 $\mu \mathrm{m}$; larg. 23-34 $\mu \mathrm{m}$; istmo $11 \mu \mathrm{m}$.

Distribuição geográfica: Estados Unidos, Europa, Ásia, África, América do Sul (Prescott et al. 1981). Brasil: Goiás (Förster 1964).

Material examinado: BRASIL. Distrito Federal: Brasília: Lagoa Bonita, 25-VIII-2006, L.M.B. Estrela \& B.M. Fonseca s.n. (UB1794); idem, 27-V-2008, L.M.B. Estrela \& B.M. Fonseca s.n. (UB1795); Lagoa dos Gansos, 8-VIII-2006), L.M.B. Estrela \& B.M. Fonseca s.n. (UB1783).

Os indivíduos observados apresentaram variação no formato das semicélulas, de acordo com a descrição e ilustrações de Förster (1964). 
Cosmarim obsoletum (Hantzsch) Reinsch var. obsoletum, Acta Soc. Senckenberg, 6:142, pl.22-D1, fig. 1-4, 1867.

Figura 32

Células grandes, 1,2 vezes mais largas que longas; constrição mediana profunda, seno fechado, dilatado nas extremidades proximais; semicélulas sub-semicirculares, ângulos basais acuminado arredondados com espessamento, margem uniformemente convexa a levemente achatada no ápice; parede celular pontuada; um cloroplasto axial por semicélula com dois pirenóides situados um ao lado do outro; vista apical elíptica espessada na parte média. Compr. 40-42 $\mu \mathrm{m}$; larg. 46-50 $\mu \mathrm{m}$; istmo 15-20 $\mu \mathrm{m}$.

Distribuição geográfica: Cosmopolita (Prescott et al. 1981). Brasil: Mato Grosso (Borge 1924), Pará (Förster 1969), São Paulo (Börge 1918, Araújo \& Bicudo, 2006), Paraná (Felisberto \& Rodrigues 2004), Distrito Federal, Lagoa Bonita, como Staurodesmus obsoletus (Hantzsch) Teiling, citada por Leite (1990).

Material examinado: BRASIL. Distrito Federal: Brasília: Lagoa Bonita, 27-V-2008, L.M.B. Estrela \& B.M. Fonseca s.n. (UB1795); idem, 10-III-2009), L.M.B. Estrela \& B.M. Fonseca s.n. (UB1796); Lagoa dos Gansos, 8-VIII-2006, L.M.B. Estrela \& B.M. Fonseca s.n. (UB1783).

* Cosmarium ocellatum Eichler \& Gutwinski var. ocellatum, Rospr. Wydz. matem-przyr. Akad. Umiej. w Krakovie 28: 164, pl. 4, fig.7. 1894. Figuras 33-34

Células médias, 1,2-1,5 vezes mais longas que largas; constrição mediana profunda, istmo estreito, seno linear, dilatado no ápice, aberto ou fechado na parte central; semicélulas subtriangulares, ângulos basais amplamente arredondados, margem superior uniformemente convexa, presença de escrobiculação central; um cloroplasto axial por semicélula com um pirenóide central; vista apical elíptica. Compr. 20-24 $\mu \mathrm{m}$; larg. 12-17 $\mu \mathrm{m}$; istmo 4-5 $\mu \mathrm{m}$.

Distribuição geográfica: Cosmopolita (Prescott et al. 1981). Brasil: São Paulo (Araújo \& Bicudo 2006).

Material examinado: BRASIL. Distrito Federal: Brasília: Lagoa Bonita, 28-VIII-2006, L.M.B. Estrela \& B.M. Fonseca s.n. (UB1794); idem, 27-V-2008, L.M.B. Estrela \& B.M. Fonseca s.n. (UB1795); Lagoa Joaquim Medeiros, 25-IV-2008, L.M.B. Estrela
\& B.M. Fonseca s.n. (UB1789); Lagoa do Cedro, 8-VIII-2006, L.M.B. Estrela \& B.M. Fonseca s.n. (UB1779); idem, 19-IX-2008, L.M.B. Estrela \& B.M. Fonseca s.n. (UB1781).

Táxon muito semelhante a $C$. granatum Brébisson ex Ralfs var. concavum Largerheim. Entretanto, o mesmo não possui o tumor mediano observado nos indivíduos encontrados neste estudo, o qual às vezes é mascarado pelo pirenóide central. Os indivíduos observados apresentaram senos desde totalmente abertos a fechados.

* Cosmarium ocellatum Eichler \& Gutwinski var. brasiliense Förster, Hydrobiologia 23 (3/4): 398. pl. 21, figs. 5-9. 1964.

Figura 35

Células médias, 1,5 vezes mais longas que largas; constrição mediana profunda, seno levemente fechado e dilatado nas duas extremidades; semicélulas subtriangulares com ângulos basais amplamente arredondados, margem superior uniformemente convexa; parede pontuada, presença de escrobiculação central; um cloroplasto axial por semicélula com um pirenóide central; vista apical elíptica. Compr. $29 \mu \mathrm{m}$; larg. $19 \mu \mathrm{m}$; istmo $4 \mu \mathrm{m}$.

Distribuição geográfica: Brasil: Goiás (Förster 1964).

Material examinado: BRASIL. Distrito Federal: Brasília: Lagoa Bonita, 27-V-2008, L.M.B. Estrela \& B.M. Fonseca s.n. (UB1795).

Essa variedade difere da variedade típica pelas células um pouco mais alongadas e pelo formato da célula, com margens mais convexas. Foi descrita por Förster (1964) em material coletado no Estado de Goiás.

Cosmarium ordinatum (Borge) West \& West var. ordinatum f. ordinatum, Trans. Linn. Soc. London, Bot., II, 5(5):251, pl. 15, fig. 14. 1896a. Figura 36

Células pequenas a médias, tão longas quanto largas; constrição mediana profunda, seno aberto; semicélula elíptica, ângulos basais retangulares, margem lateral convexa, ângulos superiores bastante arredondados, margem granular-ondulada; parede ornamentada com 5-6 séries verticais de verrugas; margem granular-ondulada, uma série de verrugas acompanhando a margem, região central lisa; cloroplasto axial, um pirenóide por semicélula; vista 
apical elíptica. Compr. 19-22 $\mu \mathrm{m}$; larg. 19-20 $\mu \mathrm{m}$; istmo $9 \mu \mathrm{m}$.

Distribuição geográfica: Cosmopolita (Prescott et al. 1981). Brasil: Mato Grosso (Borge 1924), Distrito Federal, Lagoa Bonita (Leite 1990).

Material examinado: BRASIL. Distrito Federal: Brasília: Lagoa Bonita, 27-V-2008, L.M.B. Estrela \& B.M. Fonseca s.n. (UB1795), idem, 10-III-2009, L.M.B. Estrela \& B.M. Fonseca s.n. (UB1796).

\section{** Cosmarium pericymatium var. pericymatium}

Nordstedt, Öfv. Kongl. Vet.-Akad. Förhandl. 1875(6): 29, pl. 7, fig. 26.1875.

Figuras 37-39

Celulas médias, 1,6 vezes mais longas que largas, constrição mediana suave, seno amplamente aberto; semicélulas em vista frontal aproximadamente circulares, margem crenulada; cloroplasto axial, um pirenóide por semicélula. Compr. $31 \mu \mathrm{m}$; larg. $19 \mu \mathrm{m}$; istmo $11 \mu \mathrm{m}$. Zigósporo arredondado, com parede lisa.

Distribuição geográfica: Segundo Prescott et al. (1981), a distribuição do táxon estaria restrita ao Hemisfério Norte. Não foram encontradas citações para o Brasil.

Material examinado: BRASIL. Distrito Federal: Brasília: Lagoa Bonita, 27-V-2008, L.M.B. Estrela \& B.M. Fonseca s.n. (UB1795); Lagoa Joaquim Medeiros 25-IV-2008, L.M.B. Estrela \& B.M. Fonseca s.n. (UB1789).

A população analisada apresentou medidas um pouco menores do que as mencionadas por Prescott et al. (1981), cujo comprimento seria de 40-51 $\mu \mathrm{m}$ e largura de 28-32 $\mu \mathrm{m}$. Porém, a razão comprimento/ largura e as demais características estão todas de acordo.

* Cosmarium phaseolus Brébisson ex Ralfs var. phaseolus f. minus Boldt, Öfv. Kongl. Vet.- Akad. Förhandl. 1887(2): 102. 1885.

Figuras 40-41

Células pequenas, tão longas quanto largas; constrição mediana profunda, seno aberto nas extremidades; semicélulas tendendo a reniformes, com ângulos bastante arredondados; parede celular lisa, cloroplasto axial, um pirenóide por semicélula; presença de uma pequena protuberância na região central de cada semicélula; vista lateral circular, vista apical elipsóide. Compr. 18-22 $\mu \mathrm{m}$; larg. 17-21 $\mu \mathrm{m}$; istmo 6-7 $\mu \mathrm{m}$.

Distribuição geográfica: Cosmopolita (Prescott et al. 1981). Brasil: Paraná (Felisberto \& Rodrigues 2010a).

Material examinado: BRASIL. Distrito Federal: Brasília: Lagoa Joaquim Medeiros, 8-VIII-2006), L.M.B. Estrela \& B.M. Fonseca s.n. (UB1787); Lagoa do Cedro, 19-IX-2006, L.M.B. Estrela \& B.M. Fonseca s.n. (UB1779); Lagoa Taquara, 6-V-2008, L.M.B. Estrela \& B.M. Fonseca s.n. (UB1792).

C. phaseolus apresenta grande variação intraespecífica, especialmente em relação ao formato da célula. Segundo Prescott et al. (1981), essa forma difere da típica apenas pelas dimensões $<25 \mu \mathrm{m}$ (26-29 $\mu \mathrm{m} \times 22-40 \mu \mathrm{m}$ na típica).

* Cosmarium polymorphum Nordstedt var. groenbladii Förster, Amazoniana 11 (1/2): 54, pl. 16, figs. 8-10. 1969.

Figura 42

Células médias, 1,3 vezes mais longas que largas; constrição mediana profunda, seno fechado a levemente aberto na parte distal da célula, semicélula semicircular, margem crenada, parede celular granulada destacando-se dois grânulos na região subapical de cada semicélula e também na sua porção central; cloroplasto axial, dois pirenóides por semicélula; vista apical elíptica. Compr. $30 \mu \mathrm{m}$; larg. $22 \mu \mathrm{m}$; istmo $7 \mu \mathrm{m}$.

Distribuição geográfica: Brasil: Pará (Förster 1969).

Material examinado: BRASIL. Distrito Federal: Brasília: Lagoa Bonita, 25-VIII-2006, L.M.B. Estrela \& B.M. Fonseca s.n. (UB1794); idem, 10-III-2009, L.M.B. Estrela \& B.M. Fonseca s.n. (UB1796); Lagoa Taquara, 6-V-2008, L.M.B. Estrela \& B.M. Fonseca s.n. (UB1792); Lagoa dos Gansos, 8-VIII-2006, L.M.B. Estrela \& B.M. Fonseca s.n. (UB1783).

Táxon semelhante a $C$. isthmochondrum. Este, porém, apresenta grânulos próximos ao istmo, o que não foi observado nos indivíduos deste estudo.

\footnotetext{
** Cosmarium praecisum Borge var. suecicum (Borge) Krieger \& Gerloff, Die Gattung Cosmarium 1: 92, pl. 20, fig. 9. 1962.
}

Figura 43-44 

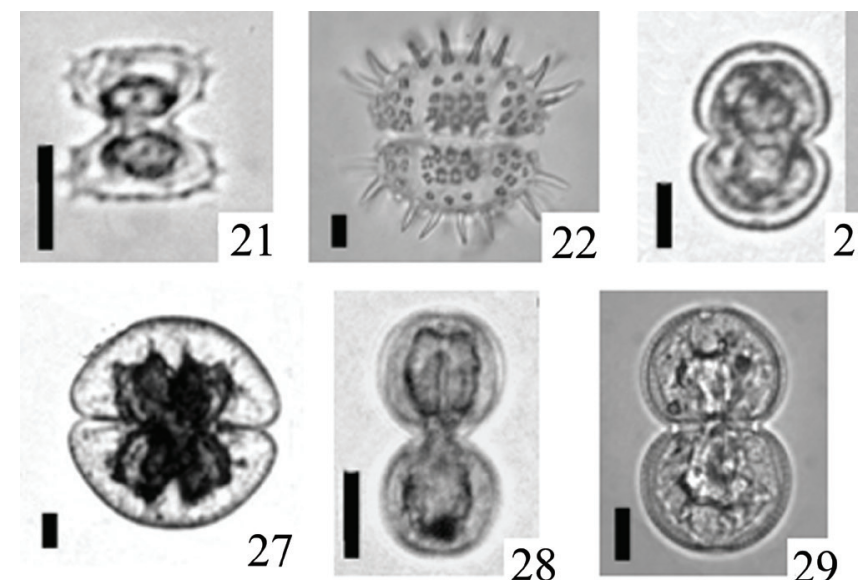

28
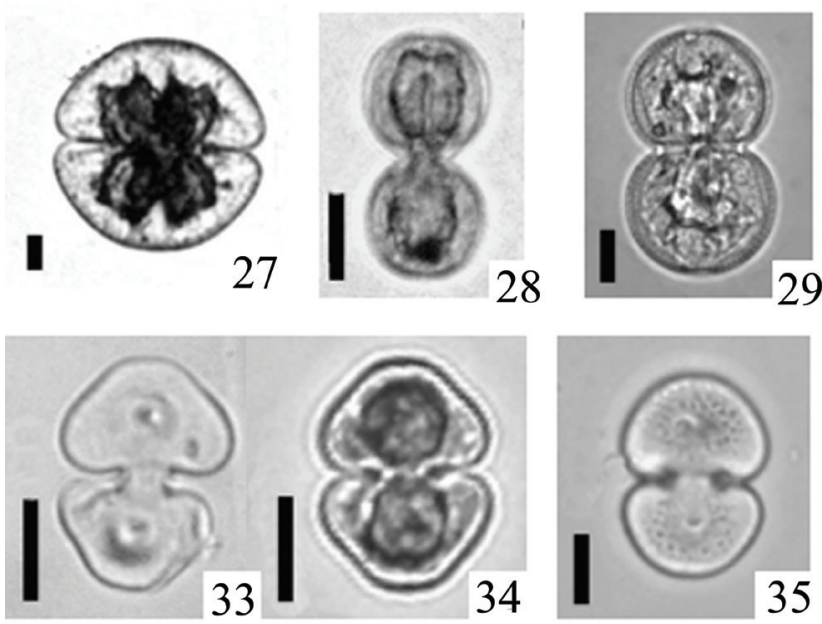

35

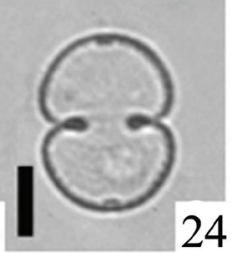

24
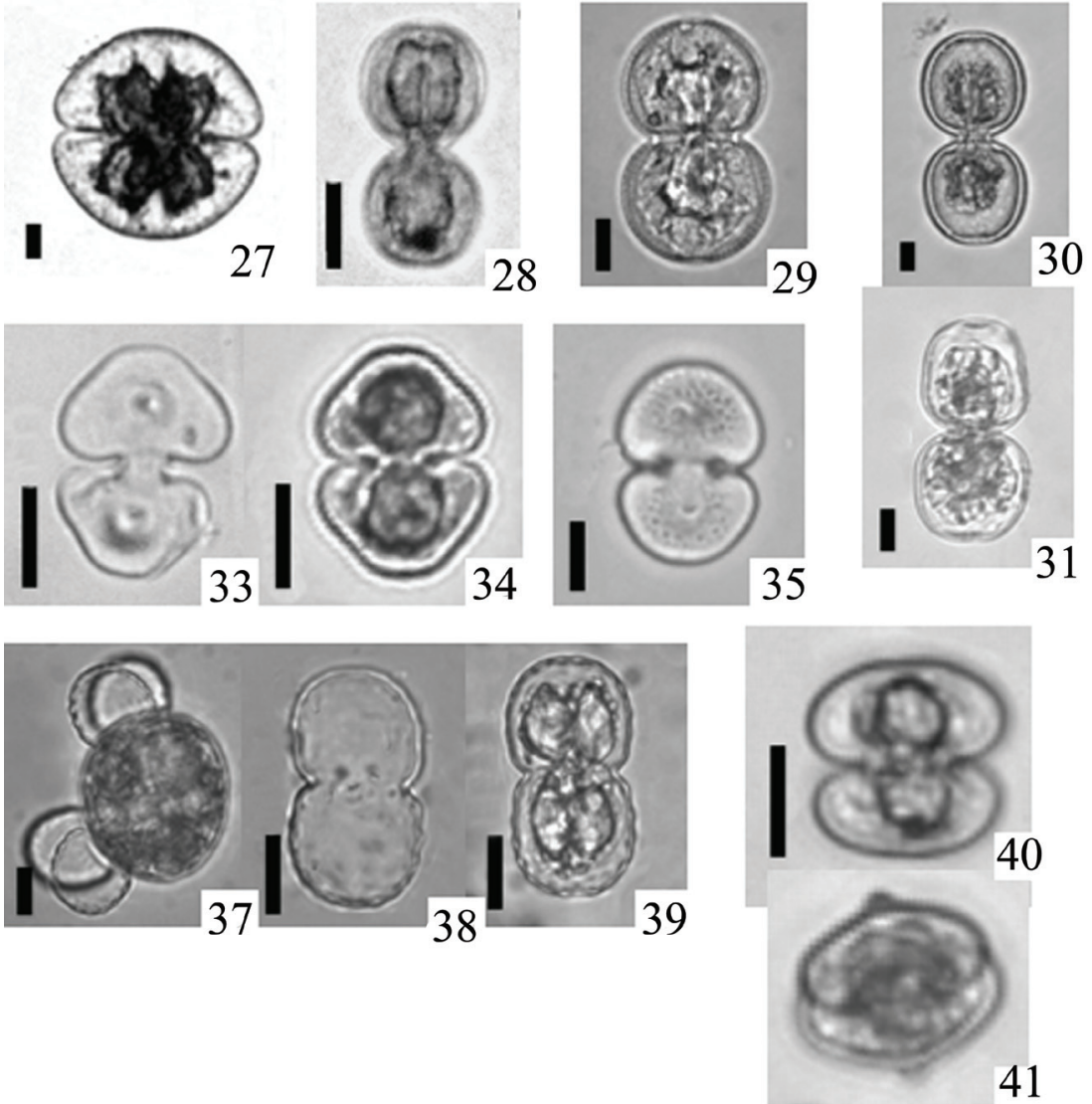
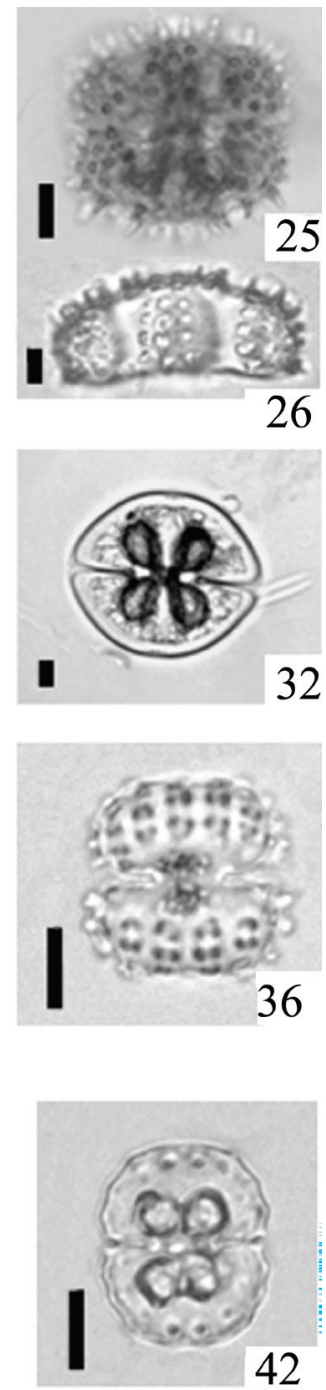

Figuras 21-42. 21. Cosmarium furcatum. 22. C. horridum. 23-24. C. laeve var. acervatum. 25-26. C. lagoense var. amoebum. 25. Detalhe da semicélula. 26. Vista frontal. 27. C. lundellii var. borgei. 28. C. moniliforme var. moniliforme. 29. C. moniliforme var. ellipticum. 30-31. C. moniliforme f. elongatum. 32. C. obsoletum. 33-34. C. ocellatum var. ocellatum. 35. C. ocellatum var. brasiliense. 36. C. ordinatum var. ordinatum f. ordinatum. 37-39. C. pericymatium var. pericymatium. 37. Zigósporo. 38. Célula sem cloroplasto. 39. Célula com cloroplasto. 40. C. phaseolus var. phaseolus f. minus. 40. Vista frontal. 41. Vista apical. 42. C. polymorphum var. groenbladii. (Barra da escala $=10 \mu \mathrm{m})$.

Figures 21-42. 21. Cosmarium furcatum. 22. C. horridum. 23-24. C. laeve var. acervatum. 25-26. C. lagoense var. amoebum. 25. Detail from the semicell. 26. Front view. 27. C. lundellii var. borgei. 28. C. moniliforme var. moniliforme. 29. C. moniliforme var. ellipticum. 30-31. C. moniliforme f. elongatum. 32. C. obsoletum. 33-34. C. ocellatum var. ocellatum. 35. C. ocellatum var. brasiliense. 36 . C. ordinatum var. ordinatum f. ordinatum. 37-39. C. pericymatium var. pericymatium. 37. Zigospore. 38. Cell without chloroplast. 39. Cell with chloroplast. 40. C. phaseolus var. phaseolus f. minus. 40. Front view. 41. Apical view. 42. C. polymorphum var. groenbladii. $(\mathrm{Scale}$ bar $=10 \mu \mathrm{m})$.

Células pequenas, tão longas quanto largas, constrição mediana profunda, seno linear e fechado, dilatado nas extremidades proximais, semicélulas trapeziformes com ângulos basais arredondados, ápice truncado, um cloroplasto axial por semicélula com um pirenóide central; presença de uma papila no centro de cada semicélula; vista apical elíptica. Compr. $8 \mu \mathrm{m}$; larg. $8 \mu \mathrm{m}$; istmo $4 \mu \mathrm{m}$.
Distribuição geográfica: Estados Unidos, Europa, Ásia (Prescott et al. 1981). Não foram encontradas citações para o Brasil.

Material examinado: BRASIL. Distrito Federal: Brasília: Lagoa Bonita, 25-VIII-2006, L.M.B. Estrela \& B.M. Fonseca s.n. (UB1794); idem, 27-V-2009, L.M.B. Estrela \& B.M. Fonseca s.n. (UB1795); 
Lagoa do Cedro, 19-IX-2006, L.M.B. Estrela \& B.M. Fonseca s.n. (UB1779).

Difere da variedade típica pelas dimensões menores e pelos ângulos basais um pouco mais pontiagudos, ainda que arredondados.

**Cosmarium pseudoconnatum Nordstedt var. pluriradians Scott \& Grönblad, Acta Soc. Sci. Fennicae, II, B, 2(8): 20, pl. 6, figs. 12-14. 1957. Figuras 45-46

Células grandes, 1,1 vez mais longas que largas, constrição mediana bastante suave, seno largo e aberto; semicélulas semielípticas; cloroplasto parietal, seis em cada semicélula com 2-3 pirenóides; parede celular pontuada; vista apical circular. Compr. 80-90 $\mu \mathrm{m}$; larg. 70-80 $\mu \mathrm{m}$; istmo 75-80 $\mu \mathrm{m}$.

Distribuição geográfica: Estados Unidos (Prescott et al. 1981). Não foram encontradas citações dessa variedade para o Brasil.

Material examinado: BRASIL. Distrito Federal: Brasília: Lagoa Bonita, 27-V-2008, L.M.B. Estrela \& B.M. Fonseca s.n. (UB1795); Lagoa Joaquim Medeiros, 8-VIII-2006, L.M.B. Estrela \& B.M. Fonseca s.n. (UB1787); idem, 22-VIII-2008, L.M.B. Estrela \& B.M. Fonseca s.n. (UB1788); idem, 25-IV-2008, L.M.B. Estrela \& B.M. Fonseca s.n. (UB1789); idem, 10-III-2009, L.M.B. Estrela \& B.M. Fonseca s.n. (UB1790).

Primeira citação para o Distrito Federal. Essa variedade diferencia-se da típica pelas células maiores (compr. 40-59 $\mu \mathrm{m}$ na var. pseudoconnatum) e pelos cloroplastos mais conspícuos. C. pseudoconnatum Nordstedt var. pseudoconnatum tem sido registrada com frequência em ambientes brasileiros (Lopes \& Bicudo 2003, Silva \& Cecy 2004, Felisberto \& Rodrigues 2004, 2008, 2010a, b, Araújo \& Bicudo 2006). Para a variedade pluriradians, entretanto, não foram encontrados registros. Há certa sobreposição de características desse táxon com Cosmarium connatum (Brébisson) Ralfs no que diz respeito a dimensões e formato das semicélulas. C. connatum, de acordo com Prescott et al. (1981), porém, apresenta cloroplastos dispostos em relação a dois pirenóides em cada semicélula. Essa característica não foi vista nos indivíduos observados e por isso manteve-se a identificação como C. pseudoconnatum var. pluriradians.
Cosmarium pseudopyramidatum Lundell var. pseudopyramidatum, Nova Acta Reg. Soc. Sci. Upsaliensis, III, 8 (2): 41, pl. 2, fig. 18. 1871. Figuras 47-49

Células grandes, 1,8 vezes mais longas que largas; constrição mediana profunda, seno fechado; semicélulas piramidal-truncadas a semielípticas, ângulos basais sub-retangulares arredondados, margem suavemente convexa e convergente para o ápice; parede celular uniforme e regularmente pontuada, um espessamento apical; cloroplasto axial com um pirenóide central em cada semicélula; vista apical elíptica. Compr. 50-62 $\mu \mathrm{m}$; larg. 25-35 $\mu \mathrm{m}$; istmo 9-15 $\mu \mathrm{m}$.

Distribuição geográfica: Cosmopolita (Prescott et al. 1981). Brasil: São Paulo (Borge 1918, Araújo 2006), Mato Grosso (Borge 1924), Pará (Förster 1969), Rio Grande do Sul (Sophia et al. 2005), Paraná (Bortolini et al. 2010).

Material examinado: BRASIL. Distrito Federal: Brasília: Lagoa Bonita, 25-VIII-2006, L.M.B. Estrela \& B.M. Fonseca s.n. (UB1794); idem, 27-V-2008, L.M.B. Estrela \& B.M. Fonseca s.n. (UB1795); idem, 10-III-2009, L.M.B. Estrela \& B.M. Fonseca s.n. (UB1796); Lagoa Joaquim Medeiros, 8-VIII-2006, L.M.B. Estrela \& B.M. Fonseca s.n. (UB1787); idem, 22-VIII-2008, L.M.B. Estrela \& B.M. Fonseca s.n. (UB1788); idem, 25-IV-2008, L.M.B. Estrela \& B.M. Fonseca s.n. (UB1789); idem, 10-III-2009, L.M.B. Estrela \& B.M. Fonseca s.n. (UB1790); Lagoa do Cedro, 19-IX-2006, L.M.B. Estrela \& B.M. Fonseca s.n. (UB1779); idem, 22-IV-2008, L.M.B. Estrela \& B.M. Fonseca s.n. (UB1780); idem, 19-IX-2008, L.M.B. Estrela \& B.M. Fonseca s.n. (UB1781); idem, 3-III-2009, L.M.B. Estrela \& B.M. Fonseca s.n. (UB1782); Lagoa Taquara, 15-VIII-2006, L.M.B. Estrela \& B.M. Fonseca s.n. (UB1791); idem, 6-V-2008, L.M.B. Estrela \& B.M. Fonseca s.n. (UB1792); idem, 29-III-2009, L.M.B. Estrela \& B.M. Fonseca s.n. (UB1793); Lagoa dos Gansos, 8-VIII-2006, L.M.B. Estrela \& B.M. Fonseca s.n. (UB1783); idem, 2-V-2008, L.M.B. Estrela \& B.M. Fonseca s.n. (UB1784); idem, 5-IX-2008, L.M.B. Estrela \& B.M. Fonseca s.n. (UB1785); idem, 20-III-2009, L.M.B. Estrela \& B.M. Fonseca s.n. (UB1786).

Segundo Prescott et al. (1981), essa espécie historicamente distingue-se de $C$. pyramidatum Brébisson pelo menor tamanho das células e pelo 
pirenóide único. Entretanto, os próprios autores reconheceram uma sobreposição de características entre ambas quando as variedades são consideradas, e chegaram a propor uma combinação das duas espécies. Leite (1990), em trabalho realizado na Lagoa Bonita, fez menção tanto à variedade e forma típicas de C. pseudopyramidatum quando à variedade maximum Börgesen. Ainda no Distrito Federal, Gomes (2007) fez referência a C. pyramidatum também para a Lagoa Bonita, e Cronberg (1977) para as lagoas Joaquim I e II. Possivelmente estão se referindo ao mesmo táxon. No presente estudo, esse táxon foi relativamente frequente, apresentando grande variedade de formas.

* Cosmarium quadrifarium Lundell var. quadrifarium f. quadrifarium, Nova Acta Reg. Soc. Up saliensis III, 8(2): 32, pl. 3, fig. 12. 1871. Figuras 50-51

Células médias, 1,3 vezes mais longas que largas; constrição mediana profunda, seno fechado; semicélulas semicirculares com ângulos basais sub-retangulares levemente arredondados; margens e ápice convexos, lados com $\sim 13$ verrugas truncadas marginais, seguidas por uma série similar de verrugas; a parte basal das semicélulas, logo acima do istmo, apresenta um tumor proeminente ornamentado com 12 a 17 grânulos arredondados; vista apical elíptica, com quatro séries paralelas de verrugas. Compr. $32 \mu \mathrm{m}$; larg. $25 \mu \mathrm{m}$; istmo $11 \mu \mathrm{m}$.

Distribuição geográfica: Cosmopolita (Prescott et al.1981). Brasil: Paraná (Silva \& Cecy 2004).

Material examinado: BRASIL. Distrito Federal: Brasília: Lagoa Bonita, 25-VIII-2006, L.M.B. Estrela \& B.M. Fonseca s.n. (UB1794); Lagoa Joaquim Medeiros, 25-IV-2008, L.M.B. Estrela \& B.M. Fonseca s.n. (UB1789).

Os indivíduos encontrados apresentaram dimensões um pouco menores que as citadas por Prescott et al. (1981). Tais autores mencionaram outras formas para esse táxon, as quais variam em relação ao número de séries paralelas nas semicélulas em vista apical. A população analisada apresentou quatro séries, enquadrando-se na f. quadrifarium.

Cosmarium quadrum Lundell var. minus Nordstedt, Acta Univ. Lund. 9: 11. 1873.

Figura 52-54

Células médias a grandes, tão longas quanto largas ou ligeiramente mais longas que largas; constrição mediana profunda, seno fechado; semicélulas sub-retangulares, margens laterais ligeiramente convexas, margens apicais quase retas, ângulos basais e apicais arredondados; parede celular granulada com série de grânulos densos, proeminentes, dispostos obliquamente; cloroplasto axial, dois pirenóides por semicélula; vista apical oblonga. Compr. 37-51 $\mu \mathrm{m}$; larg. 32-42 $\mu \mathrm{m}$; istmo $12-13 \mu \mathrm{m}$.

Distribuição geográfica: Cosmopolita (Prescott et al. 1981). Brasil: ampla distribuição, provavalmente sob outras denominações (ver comentários).

Material examinado: BRASIL. Distrito Federal: Brasília: Lagoa Bonita, 25-VIII-2006, L.M.B. Estrela \& B.M. Fonseca s.n. (UB1794); idem, 27-V-2008, L.M.B. Estrela \& B.M. Fonseca s.n. (UB1795); idem, 10-III-2009, L.M.B. Estrela \& B.M. Fonseca s.n. (UB1796); Lagoa Joaquim Medeiros, 25-IV-2008, L.M.B. Estrela \& B.M. Fonseca s.n. (UB1789); Lagoa do Cedro, 19-IX-2006, L.M.B. Estrela \& B.M. Fonseca s.n. (UB1779); Lagoa Taquara, 15-VIII-2006, L.M.B. Estrela \& B.M. Fonseca s.n. (UB1791); idem, 29-VIII-2008, L.M.B. Estrela \& B.M. Fonseca s.n. (UB1793).

As descrições e ilustrações da literatura apontam considerável sobreposição entre C. quadrum Lundell var. minus Nordstedt, C. pseudobroomei Wolle e C. margaritatum (Lundell) Roy \& Bissett quanto a medidas, padrão de granulações e formato das células (Förster 1964, Prescott et al. 1981, Silva \& Cecy 2004, Ferragut et al. 2005, Araújo \& Bicudo 2006, Bortolini et al. 2010, Felisberto \& Rodrigues 2010b). Segundo Prescott et al. (1981), C. margaritatum apresenta pontuações ao redor dos grânulos, ausentes nos outros dois táxons (embora a var. sublatum (Nordstedt) de C. quadrum também apresente pontuações). Tais pontuações não foram observadas nos indivíduos do presente estudo. Entre C. quadrum var. minus e C. pseudobroomei optou-se pelo primeiro, pela maior coerência nas medidas, especificamente em relação aos limites máximos de comprimento e largura apresentados por Prescott et al. (1981) para ambos $(38-50 \times 38-48 \mu \mathrm{m}$ para o primeiro, e $31-38 \times 27-45 \mu \mathrm{m}$ para o segundo). No Distrito Federal, Oliveira \& Krau (1970) e Philomeno (2007) registraram C. margaritatum var. margaritatum para o Lago Paranoá. Como não apresentaram ilustrações ou descrições, pode ser que tenham observado, na verdade, algum dos táxons citados anteriormente. 
* Cosmarium regnesii Reinsch var. regnesii, Act. Soc. Senckenberg 6: 116, pl. 22A III, figs. 1-5. 1867. Figura 55

Células pequenas, tão longas quanto largas; constrição mediana moderada, seno aberto, margem lateral convexa; semicélulas reniformes invertidas, ângulos arredondados, ornados com pequenos grânulos; um cloroplasto por semicélula com um pirenóide central; vista apical elíptica. Compr. 8-11 $\mu \mathrm{m}$; larg. 8-11 $\mu \mathrm{m}$; istmo 4-6 $\mu \mathrm{m}$.

Distribuição geográfica: Cosmopolita (Prescott et al. 1981). Brasil: Paraná (Felisberto \& Rodrigues 2008, 2010a, b, Bortolini et al. 2010).

Material examinado: BRASIL. Distrito Federal: Brasília: Joaquim Medeiros, 8-VIII-2006, L.M.B. Estrela \& B.M. Fonseca s.n. (UB1787); Lagoa do Cedro, 19-IX-2006, L.M.B. Estrela \& B.M. Fonseca s.n. (UB1779); idem, 22-IV-2008, L.M.B. Estrela \& B.M. Fonseca s.n. (UB1780); idem, 19-IX-2008, L.M.B. Estrela \& B.M. Fonseca s.n. (UB1781); idem, 3-III-2009, L.M.B. Estrela \& B.M. Fonseca s.n. (UB1782).

Segundo Prescott et al. (1981), esse táxon apresenta grande variação morfológica intraespecífica, podendo ser confundido com outros táxons como C. sphagnicolum West et West. Os indivíduos encontrados estão de acordo com a ilustração 3, prancha 258 , apresentada por esses autores para C. regnesii. O formato das semicélulas assemelha-se ainda a $C$. majae Strøm, porém esse não apresenta granulações.

* Cosmarim reniforme (Ralfs) Archer var. reniforme f. reniforme, Journ. Bot. 12: 92, 1874.

Figura 56

Células pequenas a médias, 1,3-1,4 vezes mais longas que largas; constrição mediana profunda, seno levemente aberto, istmo elongado; semicélulas reniformes, granulada; cloroplasto axial, com dois pirenóides por semicélula; vista apical elíptica. Compr. $19 \mu \mathrm{m}$; larg. 15-16 $\mu \mathrm{m}$; istmo $8 \mu \mathrm{m}$.

Distribuição geográfica: Cosmopolita (Prescott et al.1981). Brasil: Paraná (Felisberto \& Rodrigues 2008, 2010a, b), Mato Grosso (Camargo et al. 2009).

Material examinado: BRASIL. Distrito Federal: Brasília: Lagoa Bonita, 10-III-2009, L.M.B. Estrela \& B.M. Fonseca s.n. (UB1796); Lagoa do Cedro, 3-III-2009, L.M.B. Estrela \& B.M. Fonseca s.n. (UB1782).
Um táxon próximo seria C. portianum Archer, o qual, porém, apresenta seno bem mais aberto do que C. reniforme. Os indivíduos encontrados apresentaram dimensões menores do que as citadas por Prescott et al. (1981), 36-67 ×32-60 $\mu \mathrm{m}$. Tais autores apresentaram C. reniforme var. minor Irénée-Marie com dimensões próximas à variedade típica e recomendaram análises de outras populações.

* Cosmarium sublobatum (Brébisson) Archer var. brasiliense Borge, Ark. Bot. 1: 101, pl. 3, fig. 34. 1903.

Figura 57

Células pequenas, 1,4 vezes mais longas que largas; constrição mediana profunda, seno fechado; semicélulas trapeziformes; parede celular lisa, margens laterais convexas, margem apical truncada, ângulos basais arredondados; cloroplasto axial, com um pirenóide por semicélula. Compr. $11 \mu \mathrm{m}$; larg. $8 \mu \mathrm{m}$; istmo $3 \mu \mathrm{m}$.

Distribuição geográfica: Paraguai (Borge 1903). Brasil: Amazonas (Lopes \& Bicudo 2003), Paraná (Felisberto \& Rodrigues 2010a).

Material examinado: BRASIL. Distrito Federal: Brasília: Lagoa Joaquim Medeiros, 25-IV-2008, L.M.B. Estrela \& B.M. Fonseca s.n. (UB1789).

* Cosmarium subspeciosum Nordstedt var. subspeciosum, Öfv. Kongl. Vet.-Akad. Förhandl. 1875(6): 22, pl. 6, fig. 13. 1875.

Figura 58

Células grandes, 1,3 vezes mais longas que largas; constrição mediana profunda, seno fechado; semicélulas subtriangulares, margens convexas, com $\sim 16$ crenulações bigranuladas; parede celular granulosa com grânulos dispostos em série radiais; cloroplasto axial, dois pirenóides por semicélula. Compr. $45 \mu \mathrm{m}$; larg. $34 \mu \mathrm{m}$; istmo $12 \mu \mathrm{m}$.

Distribuição geográfica: Cosmopolita (Prescott et al. 1981). Brasil: Paraná (Bortolini et al. 2010, Felisberto \& Rodrigues 2010a, b).

Material examinado: BRASIL. Distrito Federal: Brasília: Lagoa Joaquim Medeiros, 8-VIII-2006, L.M.B. Estrela \& B.M. Fonseca s.n. (UB1787).

Segundo Prescott et al. (1981), há uma grande variedade morfológica infraespecífica nesse táxon. As diferenças entre C. speciosum Lundell e 
C. subspeciosum também não são muito claras quando as variedades são consideradas. No Distrito Federal, Giani (1984) e Giani \& Pinto-Coelho (1986) citaram C. speciosum para o Lago Paranoá. No presente estudo, manteve-se a identificação como $C$. subspeciosum pelas semicélulas tipicamente subtriangulares, bem arredondadas, enquanto C. speciosum, segundo descrição de Prescott et al. (1981) teria células sub-retangulares.

* Cosmarium subspeciosum Nordstedt var. subspeciosum f. brasiliense Förster, Amazoniana 11(1/2): 54, pl. 20, figs. 6-7. 1969.

Figuras 59-60

Células grandes, 1,5 vezes mais longas que largas; constrição mediana profunda, seno fechado, semicélulas semicirculares a subtriangulares, margens convexas, aproximadamente três séries de grânulos dispostos radialmente; no centro da semicélula, cinco séries verticais de grânulos e uma horizontal logo abaixo; cloroplasto axial, dois pirenóides por semicélula; vista apical elíptica, com ligeiro espessamento no centro. Compr. 40-48 $\mu \mathrm{m}$; larg. 27-29 $\mu \mathrm{m}$; istmo 9-10 $\mu \mathrm{m}$.

Distribuição geográfica: Brasil: Mato Grosso (Borge 1903), Pará (Förster 1969), Paraná (Silva \& Cecy 2004).

Material examinado: BRASIL. Distrito Federal: Brasília: Lagoa Taquara, 6-V-2008, L.M.B. Estrela \& B.M. Fonseca s.n. (UB1792); Lagoa dos Gansos, 2-V-2008, L.M.B. Estrela \& B.M. Fonseca s.n. (UB1784).

O presente táxon difere da forma típica pela ornamentação diferenciada no centro da semicélula.

* Cosmarium subtriordinatum West \& West var. acervatum Förster, Amazoniana 1/2: 57, Taf. 18, figs. 11-12. 1969.

Figura 61

Células médias, ligeiramente mais largas que longas; constrição mediana profunda, seno reto e fechado; semicélulas trapeziformes, ápice truncado, ângulos basais arredondados; células granuladas com verrugas bi ou tri-denticuladas distribuídas nas margens das semicélulas, formando um arranjo circular na sua face ventral; ápice achatado; em vista lateral, cloroplasto axial, com dois pirenóides por semicélula. Compr. 20-22 $\mu \mathrm{m}$; larg. 23-25 $\mu \mathrm{m}$; istmo 4-5 $\mu \mathrm{m}$.
Distribuição geográfica: Brasil: Amazonas (Förster 1969).

Material examinado: BRASIL. Distrito Federal: Brasília: Lagoa Bonita, 27-V-2008, L.M.B. Estrela \& B.M. Fonseca s.n. (UB1795); idem, 10-III-2009, L.M.B. Estrela \& B.M. Fonseca s.n. (UB1796); Lagoa do Cedro, 19-09-2006, L.M.B. Estrela \& B.M. Fonseca s.n. (UB1779).

Förster (1969) descreveu essa variedade em amostras coletadas na região amazônica. Táxons próximos são $C$. ordinatum (Börgesen) West \& West var. borgei Scott \& Grönblad (Prescott et al. 1981) e C. orthostichum Lundell var. compactum West \& West. O primeiro, porém, apresenta células mais elípticas, enquanto o segundo apresenta semicélulas subreniformes e não trapezoidais, como as observadas no presente estudo.

** Cosmarium tenue Archer var. tenue, Quart. Journ. Microsc. Sci. 8: 293. 1868.

Figura 62

Células pequenas, aproximadamente 1,4 vezes mais longas do que largas; constrição mediana profunda, seno aberto para o exterior; semicélulas elípticas com ápices ligeiramente convexos, circulares em vista lateral; cloroplasto axial, com um pirenóide. Compr. $13 \mu \mathrm{m}$; larg. 10-11 $\mu \mathrm{m}$; istmo $5 \mu \mathrm{m}$.

Distribuição geográfica: Cosmopolita (Prescott et al. 1981). Não foram encontradas citações dessa espécie para o Brasil.

Material examinado: BRASIL. Distrito Federal: Brasília: Lagoa Taquara, 6-V-2008, L.M.B. Estrela \& B.M. Fonseca s.n. (UB1792).

Segundo Prescott et al. (1981), esse táxon diferencia-se de C. bioculatum Brébisson pelo formato mais elíptico das semicélulas e pelo zigósporo com parede lisa.

* Cosmarium trilobulatum Reinsch var. abscissum (Schmidle) Krieger \& Gerloff, Die Gattung Cosmarium 1: 99, pl. 21, fig. 1. 1962.

Figura 63

Células pequenas, 1,2 vezes mais longas que largas; constrição mediana profunda, seno fechado; semicélulas trapeziformes, 3-lobadas, conjunto dos lobos basais transversalmente retangular, ângulos basais arredondados, margens laterais ligeiramente 
convexas, margens laterais superiores convergentes para o ápice, margem superior amplamente truncada; parede celular lisa; cloroplastos axiais, um pirenóide central; vista apical elíptica. Compr. $23 \mu \mathrm{m}$; larg. 18 $\mu \mathrm{m}$; istmo $6 \mu \mathrm{m}$.

Distribuição geográfica: Cosmopolita (Prescott et al. 1981). Brasil: Paraná (Silva \& Cecy 2004).

Material examinado: BRASIL. Distrito Federal: Brasília: Lagoa Bonita 27-V-2008, L.M.B. Estrela \& B.M. Fonseca s.n. (UB1795); Lagoa Joaquim Medeiros, 8-VIII-2006, L.M.B. Estrela \& B.M. Fonseca s.n. (UB1787); Lagoa Taquara, 29-VIII-2008, L.M.B. Estrela \& B.M. Fonseca s.n. (UB1793); Lagoa dos Gansos, 8-VIII-2006, L.M.B. Estrela \& B.M. Fonseca s.n. (UB1783); idem, 2-V-2008, L.M.B. Estrela \& B.M. Fonseca s.n. (UB1785).

Segundo Prescott et al. (1981), o táxon apresenta pelo menos quatro variedades, as quais diferem em relação ao formato das semicélulas. A var. abscissum difere da típica por apresentar as margens laterais divergentes ao invés de paralelas e a margem apical um pouco mais larga. Em relação à variedade típica, foi registrada no Brasil no Amazonas (Lopes \& Bicudo 2003), Mato Grosso (Camargo et al. 2009), Goiás (Felisberto \& Rodrigues 2004) e Paraná (Bortolini et al. 2010, Felisberto \& Rodrigues 2010a, Felisberto \& Rodrigues 2010b).

* Cosmarium undulatum Corda ex Ralfs var. minutum Wittrock, Nova Acta Soc. Sci. Upsaliensis, III, 7(3): 11, pl. 1, fig. 3. 1869.

Figura 64

Células médias, 1,3-1,5 vezes mais longas que largas; constrição mediana profunda, seno fechado; semicélulas subtriangulares, ápice bastante truncado, margens convexas, com 11-14 ondulações marginais acompanhadas por ondulações intramarginais; cloroplasto axial com um pirenóide por semicélula. Compr. 24-25 $\mu \mathrm{m}$; larg. 17-18 $\mu \mathrm{m}$; istmo $5 \mu \mathrm{m}$.

Distribuição geográfica: América do Norte e do Sul, Ásia, Europa (Prescott et al. 1981). Brasil: São Paulo (Araújo \& Bicudo 2006).

Material examinado: BRASIL. Distrito Federal: Brasília: Lagoa do Cedro, 19-IX-2006, L.M.B. Estrela \& B.M. Fonseca s.n. (UB1779); idem, 19-IX-2008, L.M.B. Estrela \& B.M. Fonseca s.n. (UB1781); idem, 3-III-2009, L.M.B. Estrela \& B.M. Fonseca s.n. (UB1782).
Difere da variedade típica pelas dimensões menores. Assemelha-se a C. subundulatum Wille. Porém, segundo Prescott et al. (1981), difere do mesmo pelo número de pirenóides (dois em C. subundulatum).

* Cosmarium vitiosum Scott \& Gröenblad, Acta Soc.

Sci. Fennicae, II, B, 2(8): 24, pl. 9, figs. 1-3. 1957. Figura 65

Células grandes, 1,3 vezes mais longas que largas; constrição mediana profunda, seno fechado; semicélulas subtriangulares, ângulos basais e superiores arredondados, com os basais apresentando pequenos dentículos, e os superiores denticulação coniforme proeminente; margem lateral convexa e convergente para o ápice, com 5 ou 6 dentículos; ápice com cerca de quatro ondulações; parede celular com quatro ou seis grânulos grandes subapicais; região mediana com cinco a seis verrugas e escrobiculações; cloroplasto axial, dois pirenóides por semicélula; vista apical ovalada. Compr. $40 \mu \mathrm{m}$; larg. $30 \mu \mathrm{m}$; istmo $7 \mu \mathrm{m}$.

Distribuição geográfica: América do Norte, África (Prescott et al. 1981). Brasil: Goiás (Förster 1964).

Material examinado: BRASIL. Distrito Federal: Brasília: Lagoa Bonita, 25-VIII-2006, L.M.B. Estrela \& B.M. Fonseca s.n. (UB1794); idem, 10-III-2009, L.M.B. Estrela \& B.M. Fonseca s.n. (UB1796).

Táxons próximos são C. polymorphum Nordstedt e C. isthmocondrum Nordstedt; porém os mesmos não apresentam a denticulação coniforme proeminente de C. vitiosum.

\section{Cosmarium sp. 1}

Figura 66

Células médias, ligeiramente mais longas que largas; constrição mediana profunda, seno fechado, semicélulas oblongo-trapeziformes, margens laterais convexas, margem apical truncada, ângulos basais arredondados; parede celular granulada, grânulos uniformes; cloroplasto axial, com dois pirenóide por semicélula; vista apical elíptica. Compr. $30 \mu \mathrm{m}$; larg. $28 \mu \mathrm{m}$; istmo 9-10 $\mu \mathrm{m}$.

Material examinado: BRASIL. Distrito Federal: Brasília: Lagoa do Cedro, 19-IX-2006, L.M.B. Estrela \& B.M. Fonseca s.n. (UB1779); idem, 22-IV-2008, L.M.B. Estrela \& B.M. Fonseca s.n. (UB1780); Lagoa dos Gansos, 8-VIII-2006, L.M.B. Estrela \& B.M. Fonseca s.n. (UB1783). 

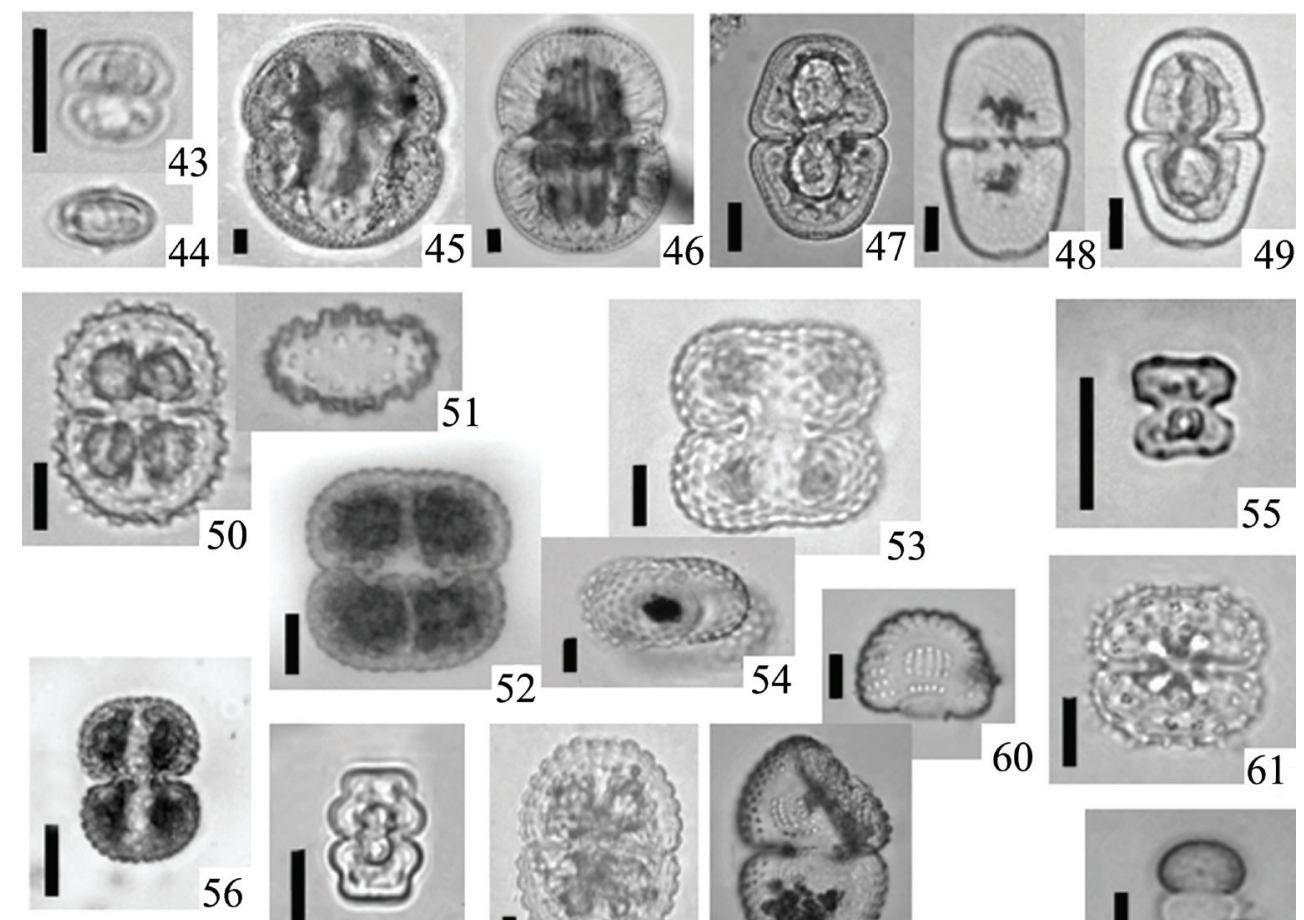
Tabela 3. Táxons de Cosmarium já citados para o Distrito Federal, Brasil mas não encontrados no presente estudo.

Table 3. Taxa of Cosmarium already found in the Federal District, Brazil but not reported in the present study.

Táxon

C. arthrodesmiforme Borge

C. bioculatum Brébisson ex Ralfs var. depressum (Schaarschmidt) Schmidle

C. brebissonii Meneghini ex Ralfs

C. clepsydra Nordstedt

Cosmarium depressum (Nägeli) Lund. f. minutum Heimer

C. dimaziforme (Grönblad) Scott \& Croasdale var. concavum Förster

C. distortum Förster var. spinuliferum Förster

C. kostei Thomasson

C. latipyramidatum Scott \& Grönblad var. trapeziforme Thomasson

C. majae Strøm

C. margaritatum (Lundell) Roy \& Bisset

C. cf. margaritiferum (Turpin) Ralfs

Cosmarium ornatum Ralfs ex Ralfs var. pseudolagoense Förster \& Eckert

Cosmarium patelliforme Borge

C. pseudotaxichondrum var. longii (Taylor) Scott

C. pseudoxanthidiforme Förster

C. pyramidatum Brébisson

Cosmarium punctulatum Brébisson

Cosmarium redimitum Borge

C. speciosum Lundell

C. sphagnicolum West \& West

C. subprotidum Nordstedt var. gregorii

(Roy \& Bisset) West \& West
Local e referência

Lagoas Joaquim I e II (Cronberg 1977)

Lago Paranoá (Mendonça-Galvão 2005), Reservatório do Descoberto, Reservatório de Santa Maria, Lagoa do Jaburu (Cronberg 1977)

Lagoa Bonita (Leite 1990, Gomes 2007)

Lagoa Bonita (Gomes 2007)

Lago Paranoá (Mendonça-Galvão 2005)

Lagoa Bonita (Leite 1990)

Lagoa Bonita (Leite 1990)

Lagoa Bonita (Leite 1990)

Lagoa Bonita (Leite 1990)

Lagoa Bonita (Gomes 2007)

Lago Paranoá (Oliveira \& Krau 1970)

Rio e Reservatório do Descoberto (Oliveira 2004)

Lagoa Bonita (Cronberg 1977, Leite 1990)

Lagoa Bonita (Leite 1990, Gomes 2007)

Lagoa Bonita (Cronberg 1977)

Lagoa Bonita (Leite 1990)

Lagoas Joaquim I e II (Cronberg 1977), Lagoa Bonita (Cronberg 1977, Gomes 2007)

Lagoa Bonita (Leite 1990)

Lagoa Joaquim I e II (Cronberg 1977)

Lago Paranoá (Giani 1984, Giani \& Pinto-Coelho 1986)

Rio e Reservatório do Descoberto (Oliveira 2004)

Lago Paranoá (Giani \& Pinto-Coelho 1986) pelo formato mais trapezoidal das semicélulas, pelas maiores dimensões e pelo número de pirenóides. C. punctulatum Brébisson, por sua vez, também apresenta apenas um pirenóide por semicélula. $\mathrm{O}$ formato das células e o cloroplasto são semelhantes a C. subtriordinatum West \& West; esse, entretanto, apresenta verrugas tri-denticuladas como ornamentação. Lopes \& Bicudo (2003) observaram indivíduos muito semelhantes em amostras da Amazônia e mantiveram em sp. por não terem encontrado nada parecido na literatura. 


\section{Cosmarium sp. 2}

Figura 67

Células pequenas, aproximadamente 1,2 vezes mais longas que largas; constrição mediana profunda, seno aberto, istmo elongado; semicélula elíptica a reniforme, granulada; vista apical elíptica. Compr. $18 \mu \mathrm{m}$; larg. $15 \mu \mathrm{m}$; istmo $6 \mu \mathrm{m}$.

Material examinado: BRASIL. Distrito Federal: Brasília: Lagoa Bonita, 25-VIII-2006, L.M.B. Estrela \& B.M. Fonseca s.n. (UB1794); idem, 27-V-2008, L.M.B. Estrela \& B.M. Fonseca s.n. (UB1795); idem, 10-III-2009, L.M.B. Estrela \& B.M. Fonseca s.n. (UB1796); Lagoa do Cedro, 3-III-2009, L.M.B. Estrela \& B.M. Fonseca s.n. (UB1782).

Os indivíduos encontrados assemelham-se a C. portianum Archer (Prescott et al. 1981) e a C. brasiliense (Wille) Nordstedt. C. portianum, porém, apresenta granulações mais conspícuas e dimensões maiores. Quanto a C. brasiliense, difere dos indivíduos observados por apresentar ápice reto e semicélulas menos reniformes.

Estudos anteriores com citações de Cosmarium para o Distrito Federal registraram 22 táxons não encontrados neste estudo, sendo a Lagoa Bonita, mais uma vez, o local com maior número de registros, com 13 táxons (tabela 3). Possivelmente o maior tamanho dessa lagoa quando comparada com as demais, associada a uma maior heterogeneidade de habitats promovida pela abundante flora de macrófitas ajudam a explicar sua elevada riqueza.

A maior parte dos táxons identificados apresentou dimensões nos limites mínimos ou, algumas vezes, abaixo das usualmente citadas na literatura. Ressalta-se a necessidade de uma revisão mais ampla do gênero, com ampliação dos limites métricos de várias espécies.

Por fim, os levantamentos florísticos realizados em regiões tropicais, mais precisamente, no centro/norte do Brasil, foram fundamentais para a identificação dos táxons encontrados no presente estudo, sugerindo padrões biogeográficos para o gênero os quais merecem ser explorados em trabalhos futuros.

\section{Agradecimentos}

Os autores agradecem ao Fundo Nacional do Meio Ambiente, pelo financiamento dado ao projeto "Restabelecimento da Integridade Ecológica e Eco-gestão nas Bacias do São Francisco e Paranoá, DF" no qual este estudo esteve inserido; à Universidade Católica de Brasília pela bolsa de IC concedida à primeira autora; à Dra. Maria das Graças Machado de Souza (UnB) pelas valiosas dicas e sugestões; ao GEEA (Grupo de Estudos de Ecossistemas Aquáticos - Universidade Católica de Brasília) pelo apoio nas coletas; aos dois revisores anônimos, pelos preciosos comentários.

\section{Literatura citada}

Abreu, C.T. 2001. Estudo do fitoplâncton ao longo de um sistema de córrego e represas nas estações de chuva e de seca, Rio Descoberto, DF. Dissertação de Mestrado, Universidade de Brasília, Brasília.

Araújo, A. 2006. Diversidade específica e de habitat dos Cosmarium de parede lisa (Zygnemaphyceae) do Estado de São Paulo. Tese de Doutorado, Universidade Estadual Paulista, Rio Claro.

Araújo, A. \& Bicudo, C.E.M. 2006. Criptógamos do Parque Estadual das Fontes do Ipiranga, São Paulo, SP. Algas, 22: Zygnemaphyceae (gêneros Actinotaenium, Cosmarium e Heimansia). Hoehnea 33: 219-237.

Bicudo, C.E.M. 1969. Contribution to the knowledge of the desmids of the state of São Paulo, Brazil (including a few from the state of Minas Gerais). Nova Hedwigia 17: 433-549.

Bicudo, C.E.M. 1988. Polymorphism in the desmid Cosmarium abbreviatum var. minus (Zygnemaphyceae) and its taxonomic implications. Acta Botanica Brasilica 21: 1-6.

Bicudo, C.E.M. \& Menezes, M. 2006. Gêneros de Algas de Águas Continentais do Brasil - Chave para identificação e descrições. Editora RIMA, São Carlos.

Borge, O. 1899. Ueber tropische und subtropische. Süsswasser-Chlorophyceen. Bihang Till K. Svenska Vet.-Akad. Handlingar, Band 24, Afd. III, 12: 1-33.

Borge, O. 1903. Die Algen der ersten Regnellschen Expedition. II. Desmidiaceen. Arkiv för Botanik 1: 71-138.

Borge, O. 1918. Die von Dr. A. Löfgren in São Paulo gessammelten Süsswasseralgen. Arkiv för Botanik 13: 1-103.

Borge, O. 1924. Die von Dr. F. C. Hoehne während der Expedition Roosevelt-Rondon gesammelten Süsswasseralgen. Arkiv för Botanik 17: 1-56.

Bortolini, J.C., Bueno, N.C., Moresco, C., Biolo, S. \& Siqueira, N.S. 2010. Cosmarium Corda ex Ralfs (Desmidiaceae) em um lago artificial urbano, Paraná, Brasil. Revista Brasileira de Biociências 8: 229-237.

Camargo, J.C., Loverde-Oliveira, S.M., Sophia, M.G., Nogueira, F.M.B. 2009. Desmídias perifíticas da baía do Coqueiro, Pantanal Matogrossense, Brasil. Iheringia 64: 25-41. 
Coesel, P.F.M., Santiago, R.D. \& Arango, G. 1988. Distributional patterns in some neotropical desmid species (Algae, Chlorophyta) in relation to migratory bird routes. Revista de Hydrobiologia Tropical 21: 197-205.

Cronberg, G. 1977. The Lago Paranoá restoration project: phytoplankton, ecology and taxonomy. Final Report. CAESB, Brasília (project PAHO - World health Organization, 77/WT/BRA/2341/04).71p.

Felisberto, S.A. \& Rodrigues, L. 2004. Periphitic desmids in Corumbá reservoir, Goias, Brazil: genus Cosmarium Corda. Brazilian Journal of Biology 64: 141-150.

Felisberto, S.A. \& Rodrigues, L. 2008. Desmidiaceae, Gonatozygaceae e Mesotaeniaceae na comunidade perifítica do reservatório de Salto do Vau (Bacia do rio Iguaçu, PR). Hoehnea 35: 235-254.

Felisberto, S.A. \& Rodrigues, L. 2010a. Periphytic algal community in artificial and natural substratum in a tributary of the Rosana reservoir (Corvo Stream, Paraná State, Brazil). Acta Scientiarum 32: 373-385.

Felisberto, S.A. \& Rodrigues, L. 2010b. Cosmarium (Desmidiaceae, Zygnemaphyceae) da ficoflórula perifítica do reservatório de Rosana, bacia do rio Paranapanema, Paraná/São Paulo, Brasil. Hoehnea 37: 267-292.

Ferragut, C., Lopes, M.R.M., Bicudo, D.C., Bicudo, C.E.M \& Vercellino, I.S. 2005. Ficoflórula perifítica e planctônica (exceto Bacillariophyceae) de um reservatório oligotrófico raso (Lago de IAG, São Paulo). Hoehnea 32: 137-184.

Förster, K. 1964. Desmidiaceen aus Brasilien. 2. Teil: Bahia, Goyaz, Piauhy und Nord-Brasilien. Hydrobiologia 23: 321-505.

Förster, K. 1969. Amazonische Desmidieen. 1. Teil: Areal Santarém. Amazoniana, 2: 5-232.

Förster, K. 1974. Amazonische Desmidieen. 2. Teil: Areal Maués - Abacaxis. Amazoniana 5: 135-242.

Giani, A. 1984. Distribuição horizontal do fitoplâncton e zooplâncton no Lago Paranoá. Dissertação de Mestrado, Universidade de Brasília, Brasília.

Giani, A. \& Pinto-Coelho, R.M. 1986. Contribuição ao conhecimento das algas fitoplanctônicas do reservatório do Paranoá, Brasília, Brasil: Chlorophyta, Euglenophyta, Pirrophyta e Schizophyta. Revista Brasileira de Botânica 9: 45-62.

Gomes, P.P. 2007. Variação espacial e temporal da comunidade fitoplanctônica da Lagoa Bonita, DF. Dissertação de Mestrado, Universidade de Brasília, Brasília.

Grönblad, R. 1945. De algis Brasiliensibus, praecipue Desmidiaceis, in regione inferiore fluminis Amazonas a Professore August Ginzberger (Wien) anno 1927 collectis. Acta Societatis Scientiarum Fennicae 2: 1-43.
Leite, A.L.T. 1990. Desmidiaceae (Chlorophyta) e os fatores físico-químicos da Lagoa Bonita, Distrito Federal, Brasil. Dissertação de Mestrado, Universidade de Brasília, Brasília.

Lopes, M.R.M. \& Bicudo, C.E.M. 2003. Desmidioflórula de um lago da planície de inundação do Rio Acre, Estado do Amazonas, Brasil. Acta Amazonica 33: 167-212.

Marinho, M.M. \& Sophia, M.G. 1997. Desmidioflórula do açude do Jacaré, município de Moji-Guaçu, SP, Brasil. Hoehnea 24: 37-53.

Mendonça-Galvão, L. 2005. Comunidade planctônica e o processo de restauração do Lago Paranoá, DF. Tese de Doutorado, Universidade de Brasília, Brasília.

Murakami, E.A. 2000. Variação sazonal do fitoplâncton e de algas epífitas associadas aos bancos de Polygonum ferrugineum Weed na Represa do Rio Descoberto, DF. Dissertação de Mestrado, Universidade de Brasília, Brasília.

Oliveira, E.C.A. 2004. Comunidades fitoplanctônicas em ambientes lêntico e lótico na Bacia do Rio Descoberto, DF, em períodos de chuva e seca. Dissertação de Mestrado, Universidade de Brasília, Brasília.

Oliveira, L.P.H. \& Krau, L. 1970. Hidrobiologia geral aplicada particularmente a veiculadores de esquistossomos - hipereutrofia, mal moderno das águas. Memórias do Instituto Oswaldo Cruz 68: 89-118.

Padovesi-Fonseca, C. 2005. Caracterização dos ecossistemas aquáticos do Cerrado. In: A. Scariot, J.C. Sousa-Silva \& J. Felfili (orgs.). Cerrado: Ecologia, Biodiversidade e Conservação. Ministério do Meio Ambiente, Brasília, pp. 417-429.

Philomeno, M.G. 2007. A comunidade fitoplanctônica e a restauração do Lago Paranoá, Brasília, DF. Tese de Doutorado, Universidade de Brasília, Brasília.

Prescott, G.W., Croasdale, H.T. Vinyard, W.C. Bicudo, C.E.M. 1981. A Synopsis of North American Desmids. Part II. Desmidiaceae: Placodermae Section 3. University of Nebraska Press, Lincoln.

Silva, F.A.M. da, Assad, E.D. \& Evangelista, B.A. 2008. Caracterização climática do bioma Cerrado. In: S.M. Sano, S.M.P. Almeida \& J.F. Ribeiro (eds.). Cerrado: Ecologia e Flora. Embrapa Informação Tecnológica, Brasília, pp. 69-87.

Silva, S.R.V.F \& Cecy, I.I.T. 2004. Desmídias (Zygnemaphyceae) da área de abrangência da Usina Hidrelétrica de Salto Caxias, Paraná, Brasil, I: Gênero Cosmarium. Iheringia 59: 13-26.

Sophia, M.G. 1999. Desmídias de ambientes fitotélmicos bromelícolas. Revista Brasileira de Biologia 59: 141-150.

Sophia, M.G., Dias, I.C. \& Araújo, A.M. 2005. Chlorophyceae and Zygnemaphyceae from the Turvo State Forest Park, state of Rio Grande do Sul, Brazil. Revista Brasileira de Biologia 51: 85--107.

Sophia, M.G. \& Huszar, V.L.M. 1996. Planktonic desmids of three Amazonian systems (Lake Batata, Lake Mussará and Trombetas River), Pará, Brazil.Amazoniana 14: 75-90. 